\title{
Research Paper \\ The mediating role of risk perception and anxiety sensitivity in the structural relations of neuroticism and extravertion with the psychological and behavioral problems of corona virus
}

\author{
Mostafa Zarean', Mohammad Nasiri ${ }^{2}$, Mahsa Seyyed Razzaghi ${ }^{3}$, Kiana Azizi ${ }^{3}$, Mehran Golzari Amjad ${ }^{3}$, Soheila Maboud ${ }^{3}$ \\ 1. Assistantn Professor, Department of Psychology, University of Tabriz, Tabriz, Iran. \\ 2. Ph.D. in Health Psychology, Department of Psychology, Kharazmi University, Tehran, Iran. \\ 3. M.A. in Clinical Psychology, Department of Psychology, University of Tabriz, Tabriz, Iran.
}

Citation: Zarean M, Nasiri M, Seyyed Razzaghi M, Azizi K, Golzari Amjad M, Maboud S. The mediating role of risk perception and anxiety sensitivity in the structural relations of neuroticism and extravertion with the psychological and behavioral problems of corona virus. $\mathbf{J}$ of Psychological Science. 2021; 20(103): 1039-1053.

URL: https://psychologicalscience.ir/article-1-1198-fa.html
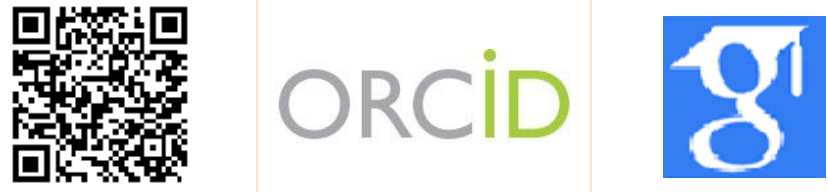

\section{A R T I C L E I F O A B T R A C T}

\author{
Keywords: \\ Risk Perception, \\ Anxiety Sensitivity, \\ Neuroticism, \\ Extroversion, \\ Corona virus
}

Background: Personality components alongside with other psychological characteristics such as risk perception, anxiety sensitivity, and metacognitive belifs are considered as the most important and effective factors to pandemic. Neuroticism and extraversion have attracted more attention of the researchers, however, the mediatory role of psychological constructs in corona pandemic have been less investigated.

Aims: The present study is aimed at investigating the mediatory role of risk perception and anxiety sensitivity in the structural relations of neuroticism and extravertion with the psychological and behavioral problems of Corona virus.

Methods: This study had a descriptive correlational design. The population of the study was all Iranian community individuals who lived in the country within he first 6-month of the 2020 year. A sample of 649 participants enrolled to the study through purposeful sampling. To collect the data, the psychological and behavioral problems of Corona virus questionnaire (authors' designed), along with anxiety sensitivity index (Reiss, Peterson, Gursky, \& McNally, 1986), big five personality (Donnellan, Oswald, Baird, \& Lucas, 2006), and risk perception (Benthin, Slovic, \& Severson, 1993) scales were used.

Results: The evaluation of the hypothesized model using goodness-of-fit indices indicated that our proposed model fits with the measured model $(\mathrm{CFI}=0 / 96, \mathrm{NFI}=0 / 94$, and RMSEA=0/054). Statistical analyses revealed that risk perception and anxiety sensitivity could play mediating role in the structural relations of neuroticism and extravertion with the psychological and behavioral problems of Corona with standard coefficients of $-0 / 052$ and $0 / 161(p<0 / 05)$. Also, neuroticism has significant effect on the psychological and behavioral problems of Corona with the mediation of risk perception with standard coefficient of $0 / 100(p<0 / 05)$.

Conclusion: It assumed that the psychological and behavioral problems of Corona virus is effected by some psychological factors through direct and indirect ways and their inclusion in the comprehensive plans of health system is preferred.
Received: 28 Mar 2021

Accepted: 21 Apr 2021

Available: 23 Sep 2021

\footnotetext{
* Corresponding Author: Mostafa Zarean, Assistantn Professor, Department of Psychology, University of Tabriz, Tabriz, Iran.
}

E-mail: Zarean@tabrizu.ac.ir

Tel: (+98) 9143080767

2476-5740/ ( 2021 The Authors. This is an open access article under the CC BY-NC-ND license

(https://creativecommons.org/licenses/by-nc/4.0/). 


\section{Extended Abstract}

\section{Introduction}

Corona viruses are one of the main contributors to illnesses and affect primarily the breathing system in human being. Pandemics like the current situation are not a medical phenomenon, and have impact on the quality of life of individuals and society, and could lead to social functioning (Banerjee, 2020). Researches on the social reactions to previous pandemics also show that several psychological vulnerabilities are playing role in this issue such as individual differences in variables like intolerance of uncertainty, perceived vulnerability to illness, and anxiety sensitivity (Taylor, 2019a). Among these components, differences in personality traits are crucial in how people has been affected from critical conditions (Commodari, 2017). Research has also shown that personality traits have effects on psychological distress in both pandemic and nonpandemic situations. For instance, high rates of psychoticism are associated with high levels of psychological distress, and neuroticism has relationships with low levels of psychological distress (Kendler, Gatz, Gardner \& Pedersen, 2006).

Although the major part of the distress level for an accident is determined by individuals' personality, however, other factors are also relevant such as their beliefs about the accident and threat perception levels (Xie, Stone, Zheng \& Zhang, 2011). Danger perception is related to the mental recognition and judgement about the characteristics and the severity of a danger in individual level (Chauvin, Hermand, \& Mullet, 2007). With the increase in danger perception about an illness, the protective activities are also increasing.

Anxiety sensitivity as a personality trait has also relationship with the anxiety toward infectious disease and other related variables (e.g. quality of life) in pandemic situation (Taylor, 2019b). Anxiety sensitivity is referred to a belief that the experience of anxiety/fear leads to the feeling of more shame and anxiety (Reiss, Peterson, Gursky \& McNally, 1986). Studies show that with the high levels of anxiety sensitivity, people experiencing more stress (Wheaton et al. 2012).
Despite the important theoretical basis for the relationships between neuroticism, extraversion, danger perception and anxiety sensitivity with psychological and behavioral problems, there is limited knowledge about their relationships among Iranian residents in the Corona pandemic. Therefore, the current study is designed to answer the question that if there is any relationship between neuroticism and extraversion with the psychological and behavioral problems related to Corona with testing the mediatory role of danger perception and anxiety sensitivity.

\section{Method}

This study had a cross-sectional correlational design. Research data is gathered using online platform by researchers in the Department of Psychology at the University of Tabriz on March 2020. The statistical population was all individuals who were living in Iran and were engaged with the news and circumstances of Corona in recent months. The sample of the study consisted of 649 individuals ( $72 \%$ women, and $28 \%$ men) who participated and filled the online questionnaire after giving the informed consent. To collect the data, research group used their own questionnaire for psychological and behavioral problems due to Corona, along with Anxiety Sensitivity Index (Reiss, Peterson, Gursky \& McNally, 1986), Big Five Personality (Donnellan, Oswald, Baird, \& Lucas, 2006), and Risk Perception Scales (Benthin, Slovic, \& Severson, 1993). To analyzed the data, we performed structural equation modeling using AMOS-24 software.

\section{Results}

Table 1 represents the descriptive statistics and correlations between the variables of the study. The proposed structural model for the study is also presented in figure1. 
Table 1. Correlation matrix of research variables

\begin{tabular}{cccccccccc}
\hline variables & 1 & 2 & 3 & 4 & 5 & M & SD & Skewness & Kurtosis \\
\hline Extroversion & 1 & & & & & 12.63 & 3.77 & -0.196 & -0.640 \\
Neuroticism & ${ }^{* *}-0.153$ & 1 & & & & 11.31 & 3.41 & 0.311 & -0.520 \\
Risk perception & ${ }^{* *}-0.121$ & ${ }^{* *} 0.336$ & 1 & & & 19.18 & 4.05 & 0.866 & 1.089 \\
Anxiety sensitivity & ${ }^{* *}-0.193$ & ${ }^{* *} 0.342$ & ${ }^{* *} 0.277$ & 1 & & 25.48 & 12.69 & 0.450 & -0.343 \\
Corona problems & ${ }^{*}-0.095$ & ${ }^{* *}-0.278$ & ${ }^{* *}-0.263$ & ${ }^{* *} 0.365$ & 1 & 66.47 & 10.45 & -0.538 & 0.639 \\
\hline
\end{tabular}

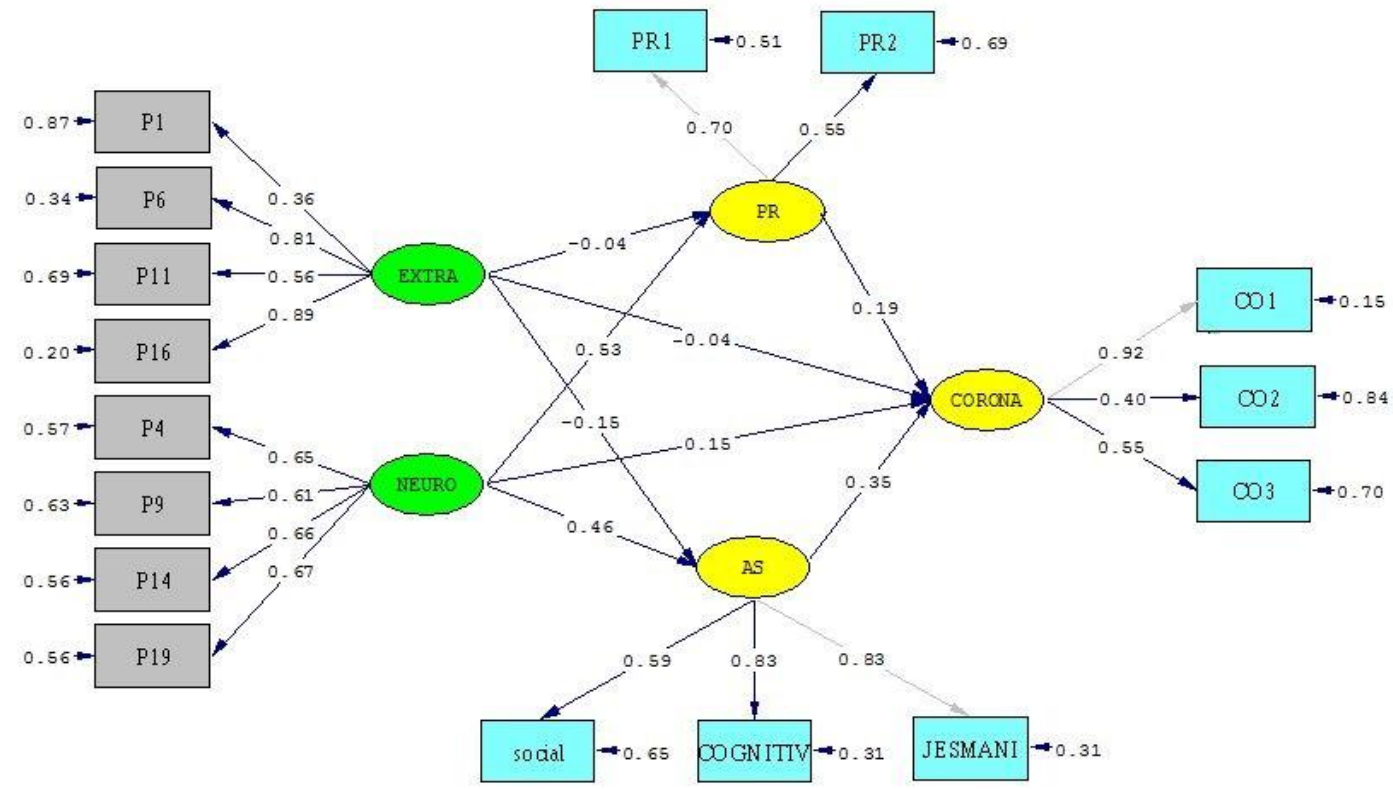

Chi-Square $=285.22, \mathrm{df}=95, \mathrm{P}-\mathrm{value}=0.00000, \mathrm{RMSEA}=0.056$

Figure 1. Structural model of the study with standard coefficients

\section{Conclusion}

With the expansion of Corona and its mortality, the number of studies related to Covid-19 is also increasing, each of which looks at the issue from different view of point. The present study also showed that personality factors have both direct and indirect role (via the mediatory role of risk perception and anxiety sensitivity) in the emergence of underlying psychological and behavioral problems. These results are consistent with the findings of Taylor (2019b), Hill et al. (2011), Xie et al. (2011), Wheaton et al. (2012), and Chauvin et al. (2007).

To explain our findings, its noteworthy that individuals with different levels of neuroticism and extroversion has different levels of risk perception and anxiety sensitivity, and hence, they experience different consequences from a single environmental stressor (such as pandemic disease). For instance, extrovert people experience more positive emotions in comparison with introverts (Lucas, \& Diener,
2001). Nevertheless, when anxiety sensitivity is interacting with extroversion, leads to avoidance from stressful situations causing more attention to somatic symptoms (Kumar, Vats, Sonare, Kachhawha, 2015). In contrast, due to the lack of appropriate adjustment skills, individuals with high levels of neuroticism are affected more by emotional threats and stimulus, which is in turn, cause more tension during the pandemic (Lucas, \& Diener, 2001). When high risk perception and anxiety sensitivity interact with neuroticism, they could intensify the effects of neuroticism and lead to avoidance from negative emotions as well as increased attention towards somatic symptoms (Chauvin et al. 2007).

According to the current research findings, we concluded that the psychological and behavioral problems related to corona virus are related to psychological factors both directly and indirectly, and its worthy to be recognized in micro and macro health management policies 


\section{Monthly Journal of Psychological Science}

Ethical Considerations

Compliance with ethical guidelines: Ethical considerations like gaining the informed consent of the participants and the confidentiality of responses were considered in this research. Funding: This study was conducted independently with no financial support.
Vol. 20, No. 103, Autumn(October) 2021

Authors' contribution: The first author was the senior author and others were co-authors with equal contribution.

Conflict of interest: The authors declared no potential conflicts of interest with respect to the research, authorship, and/or publication of this article.

Acknowledgments: The authors thank all participants for their assistance in the conduct of the study. 


\title{
نقش ميانجى ادراكى خطر و حساسيت اضطرابى در رابطه نوروز ائى و برونكرايى با مشكلات روانشناختى و رفتارى ويروس كرونا
}

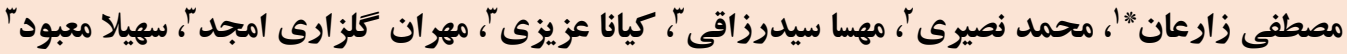

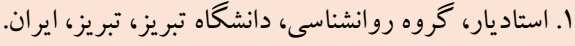

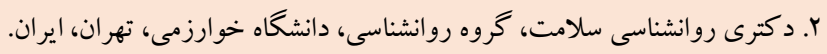

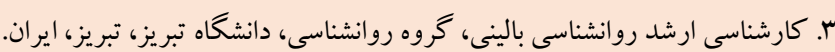

\section{جكيده}

زمينه: عوامل شخصيتى در كنار ساير ويزگىهاى روانشناختى از جمله ادراك خطر، حساسيت اضطرابى و باورهاى فراشناختى بر پايه

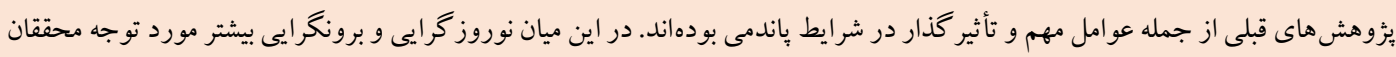

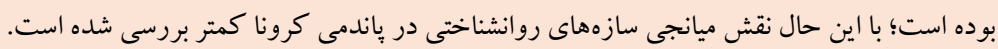
هدف: يُزوهش حاضر با هدف مطالعه نقش ميانجى ادراكى خطر و حساسيت اضطرابى در رابطه نوروز گر ايى و برونگر ايى با مشكلات

$$
\text { روانشناختى و رفتارى ويروس كرونا انجام شد. }
$$

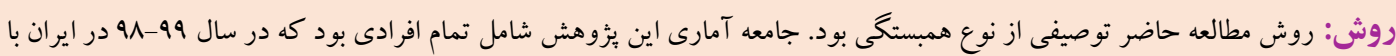

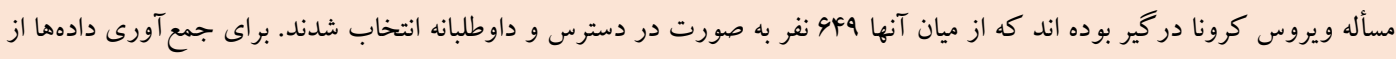

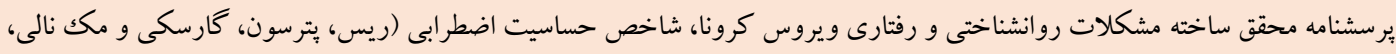

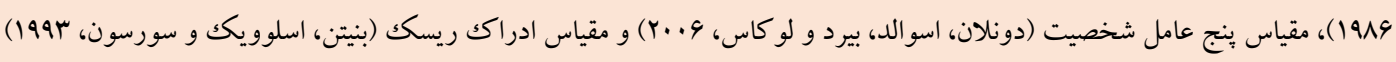

$$
\text { استفاده گرديد. }
$$

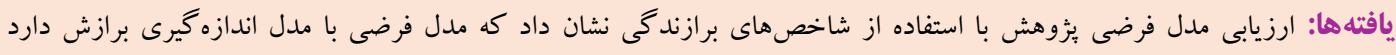

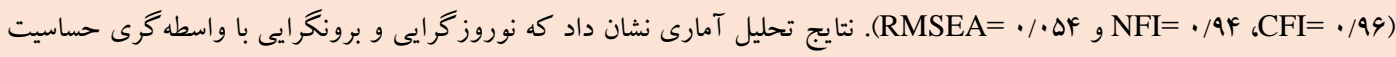

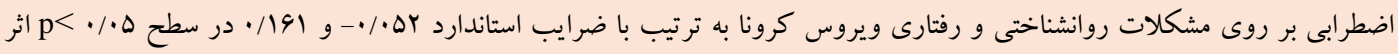

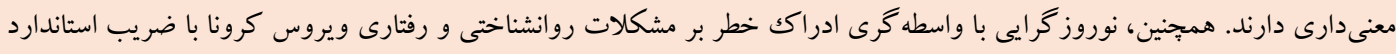

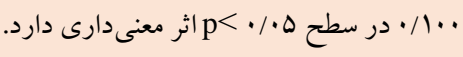

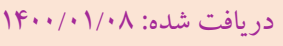
نتيجه كيرى: بر اساس نتايج بزوهش به نظر مىرسد مشكلات روانشناختى و رفتارى مربوط به ويروس كرونا به صورت مستقيم و غيرمستقيم تحت تأثير عو امل روانشناختى قرار دارد و شايسته است در برنامههاى مديريت بهداشتى كلان مورد توجه قرار گيردي.
مشخصات مقاله

كليدوازهها:

ادراكى خطر،

حساسيت اضطر ابى،

نوروز گرايى،

برونگرايى، توروزي،

ويروس كرونا

* نويسنده مسئول: مصطفى زارعان، استاديار، گروه روانشناسى، دانشخاه تبريز، تبريز، ايران.

رايانامه: Zarean@tabrizu.ac.ir

تلفن: V9V. 
كيفيت ترى دارند (هريس، انخليسى، هارمس، گروس و جكسون، IV IV)، از سطح بالايى از حمايت اجتماعى ادراكك شده برخوردار هستند (تان و

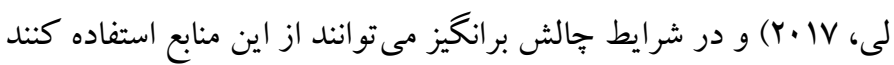

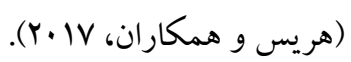

علاوه بر ويز گىهاى شخصيتى، باورهاى افراد در مورد هاد حادثه و ميزان

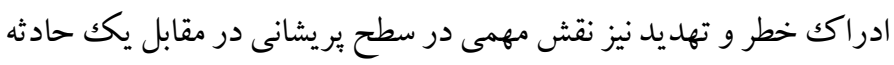

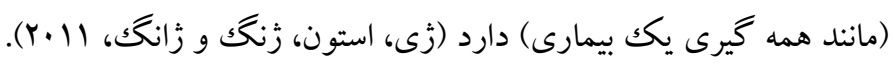

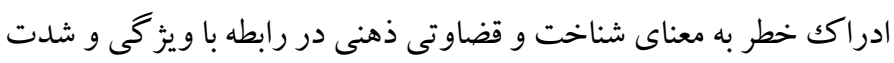

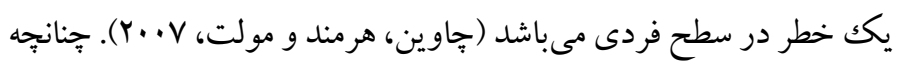
ادراك خطر از يكك بيمارى افزايش يابد، به تبع آن انجام اقدامات

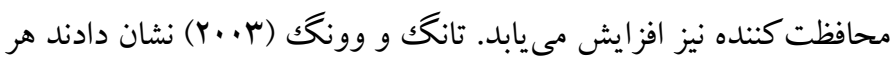

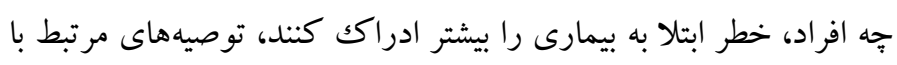

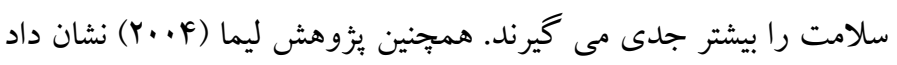

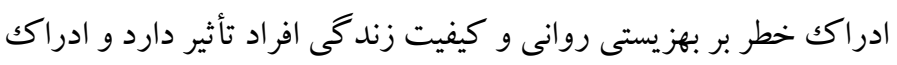

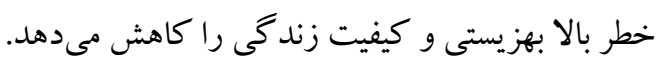
حساسيت اضطر ابى نيز در قامت يكك خصيصه شخصيتى، با اضطر اب ابتلا به بيمارى عفونى در زمان إيدمى و متغيرهاى مرتبط با آن (ماند كيفيت

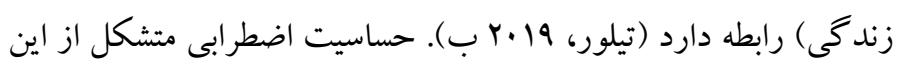

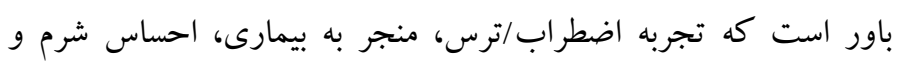

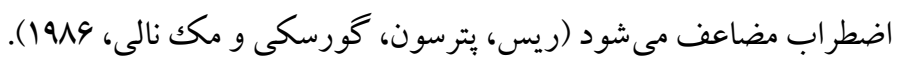

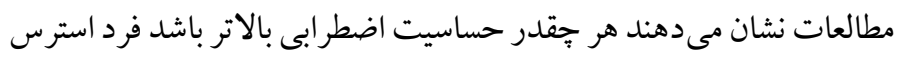

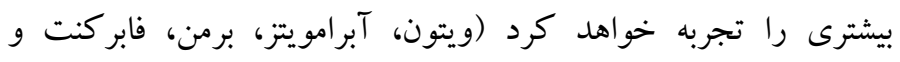

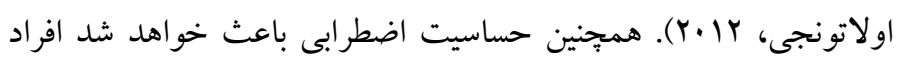
افكار و اعمال وسواسى بيشترى از خود نشان دهند (لايوسا، كوليمور،

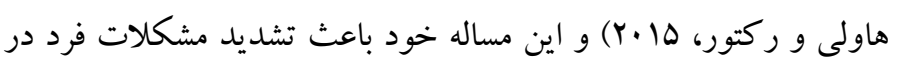
شرايط بحر انى مىشود.

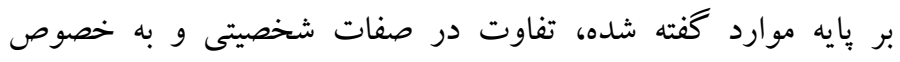

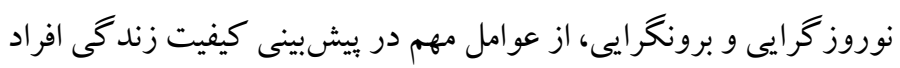

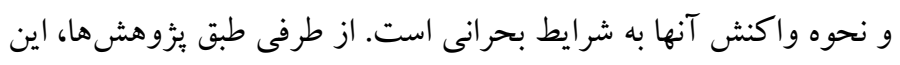

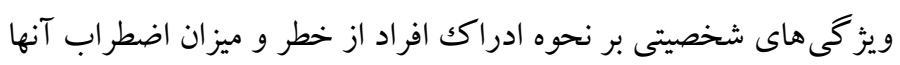

${ }^{3} \cdot$ pandemic
1. Severe Acute Respiratory Syndrome (SARS)-CoV

${ }^{2}$. Middle East Respiratory Syndrome (MERS)-CoV

مقالمه

كرونا ويروسها يكى از عوامل اصلى ايجادكننده بيمارى هستند كه در

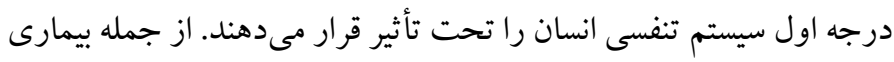

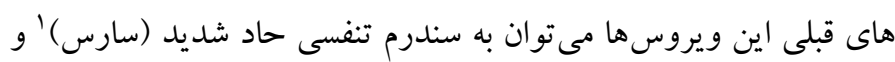

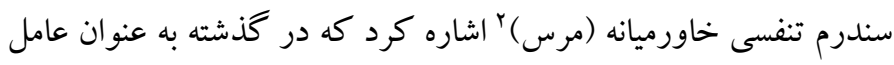

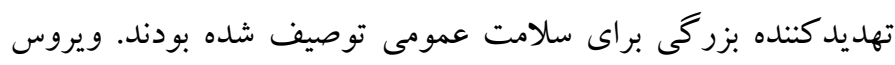

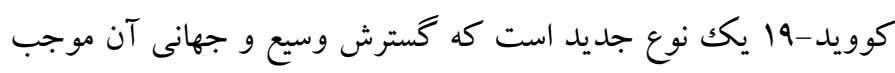

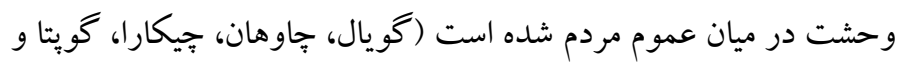

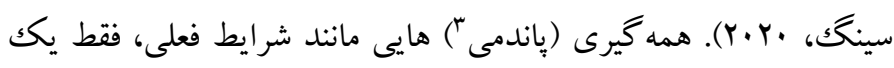

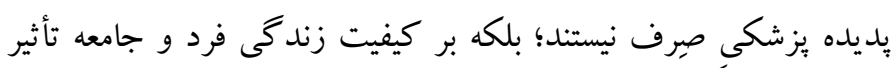

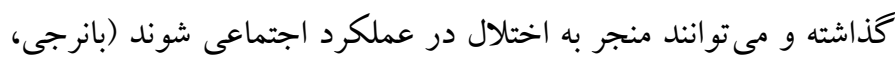

(Y.Y.

نوروز گرايى يكى از عوامل بسيار مهم در نحوه تأثير يذيرفتن افراد از شرايط بحرانى (كومودرى، Y.|lV) و همين طور شيوه واكنش به بيمارى (هيل،

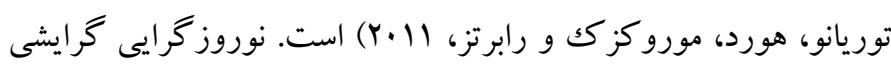
خلقى و وايدار نسبت به اختلالات عملكردى است كه با تمايل به تجربه مورديه

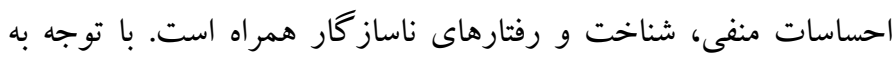

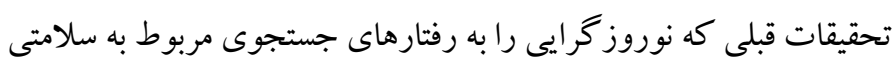

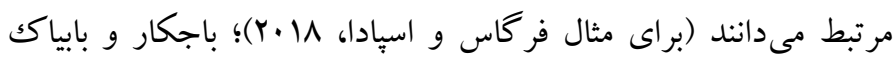
نو نو (Y.Y. )

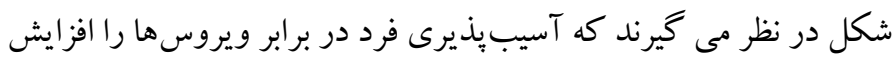

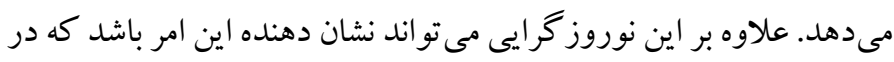

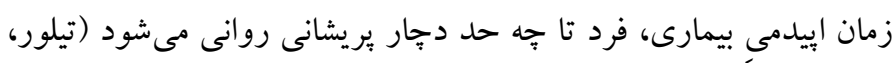

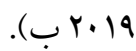
برونگر ايى يكى ديخر از عو املى است كه واكنش فرد در شرايط بحرانى را

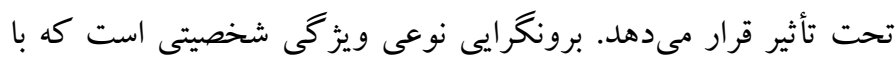

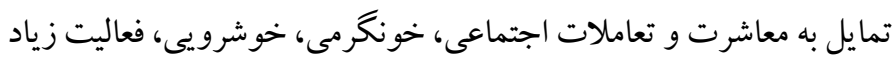

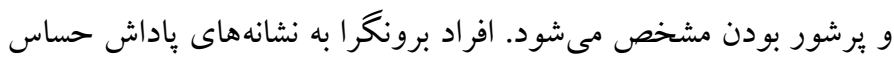

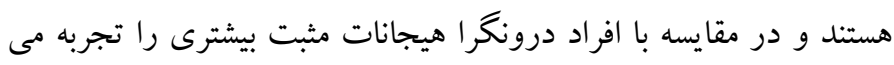

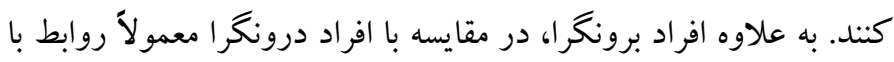


بنابراين هدف از يزوهش حاضر پِاسخ به اين سؤال است كه آيا

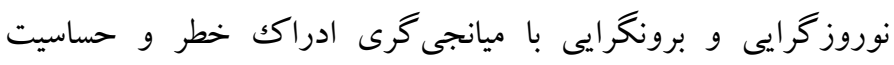

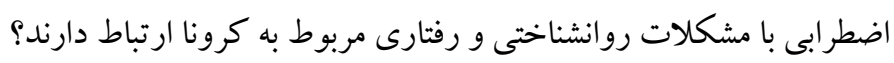

روش الف) طرح هئوهش و شر كت كنند كان: اين يُوهش در قالب يك طرح همبستخى مقطعى بود. دادههاى تحقيق از طريق برسشنامه آنلاين در بازه

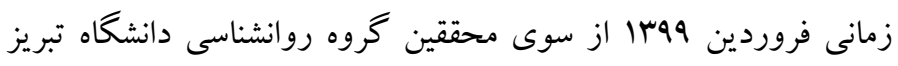

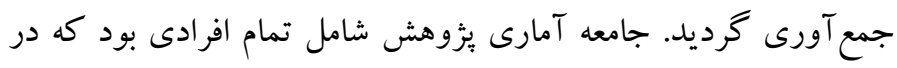

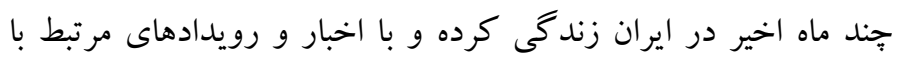

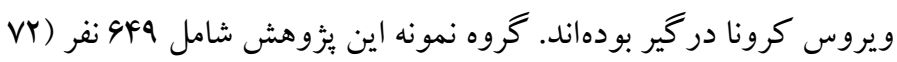

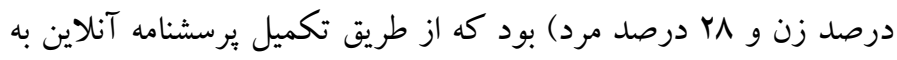
صورت داوطلبانه و با اخذ رضايت كتبى اقدام به شركت در اين يثروهش

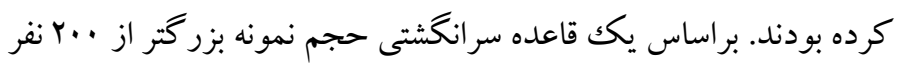

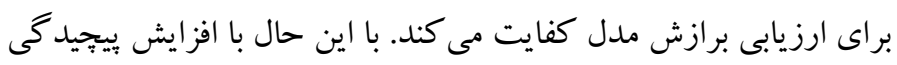
مدل، حجم نمونه بيشترى نياز است (كلاين، ها ·Y). بنابر اين در سالهاى

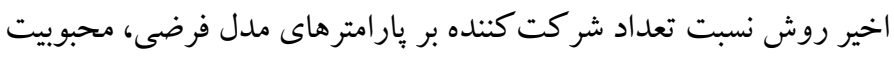

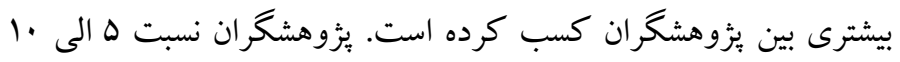

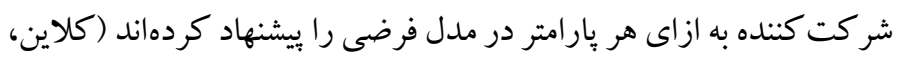

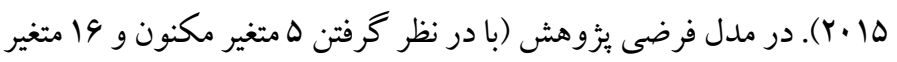

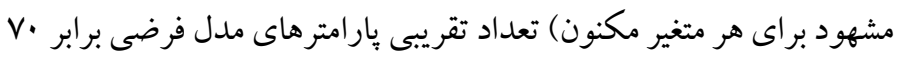

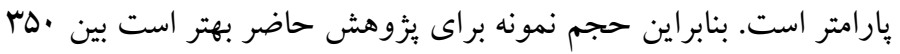

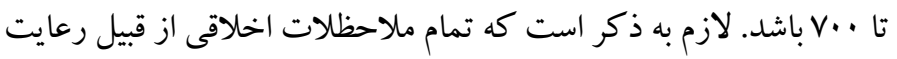

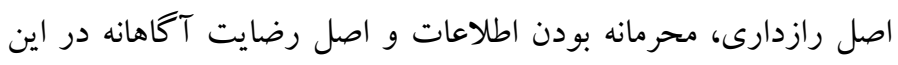
يزوهش رعايت شد. مجوز اجراى يزوهش حاضر بر روى افراد نمونه از

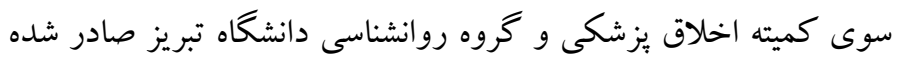

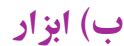

يرسشنامه مشكلات روانشناختى و رفتارى كرونا: در ارتباط باويروس كرونا

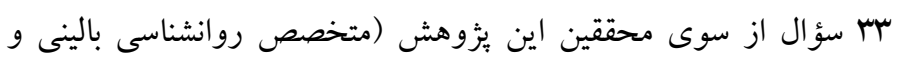

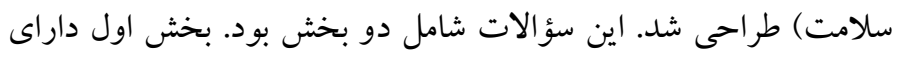
rا سؤ ال با شيوه ياسخدهى صحيح (نمره يكك) يا غلط (نمره صفر) با الهام
در مواجهه با شرايط بحرانى تأثير كذاشته و از اين طريق عملكرد

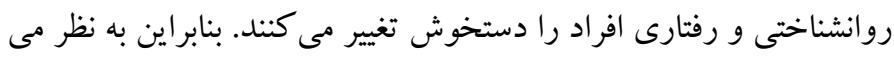

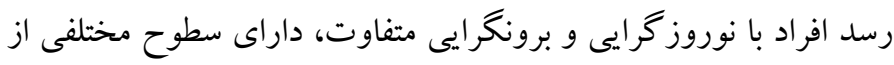
ادراكك خطر و حساسيت اضطرابى بوده و از اين رو بيامدهاى متفاوتى از يكك استرسور محيطى يكسان (همانند همه گيرى بيمارىها) را تجربه كنند.

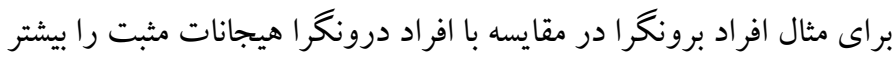

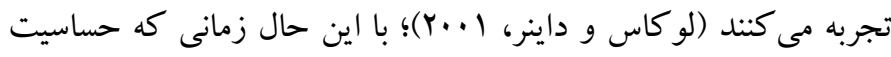

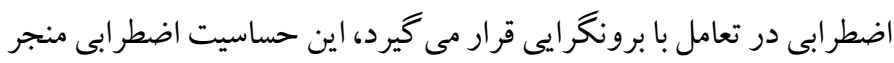
به اجتناب از موقعيت هاى استرسزا شده و با افزايش توجه فرد به بر نشانهاي

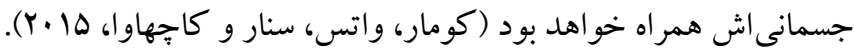

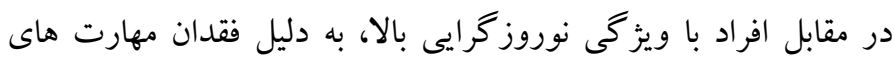

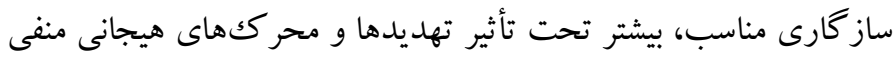
قرار مى گيرند و اين مسأله باعث تجربه تنش بيشتر در زمان إيدمى بيمارى لهاريا

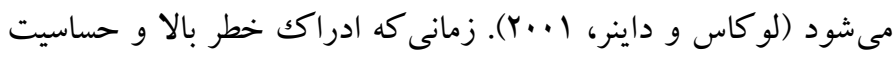

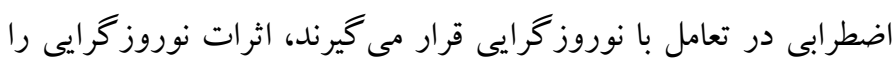

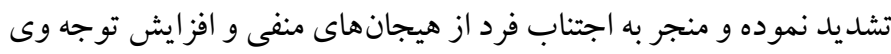

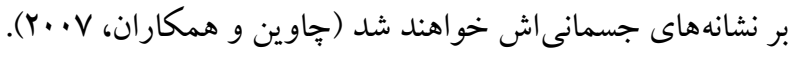

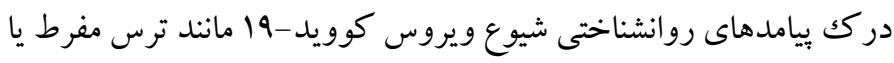

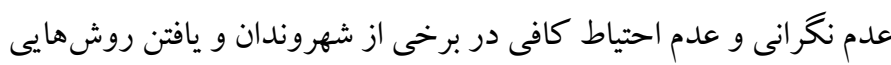
مبتنى بر شواهد به منظور بررسى و شناخت اين موضوعات بسيار مهم و و

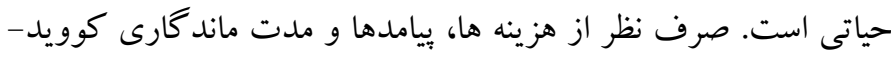

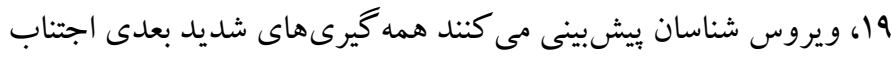

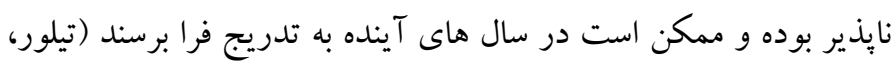

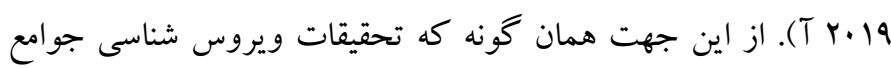
انسانى را به دستيابى به يروتكل هايى جهت تأمين سلامت جسمى رهنمون

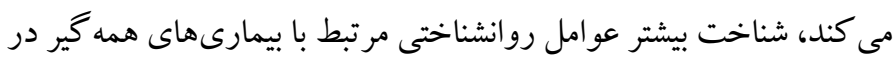
طراحى مداخلاتى جهت حفظ سلامتروانى جوامع در همه گيرىهاى

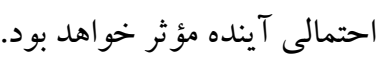

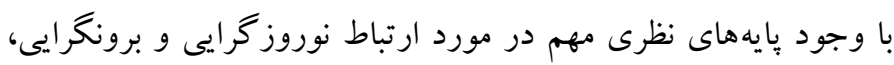

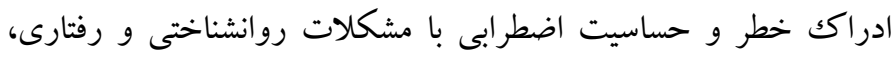
تاكنون به مطالعهاى دست نيافتهايم كه به بررسى همزمان اين متغيرها در

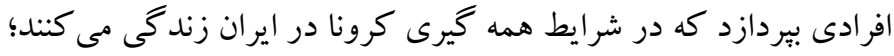


عامل شخصيت از سوى كرمى، سبزى، جِينى، حرفه دوست و طيرانىراد

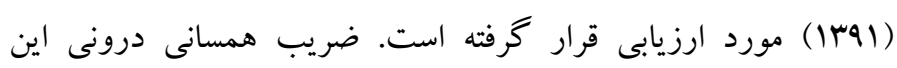
يرسشنامه كه توسط آلفاى كرونباخ محاسبه شده براى ينج بعد شخصيت

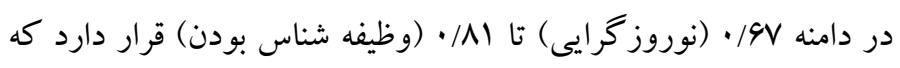
نشان مىدهد ضرايب اعتبار در حد قابل قبول هستند. ضريب پايايى كل

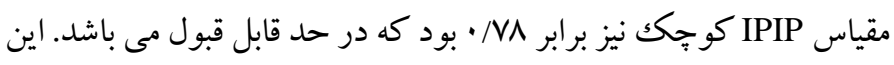

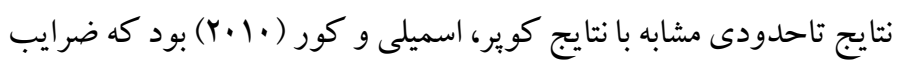

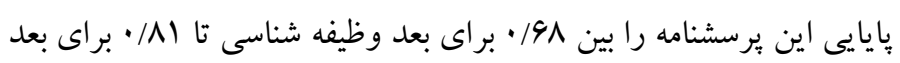

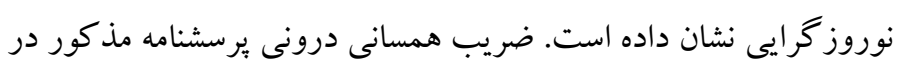

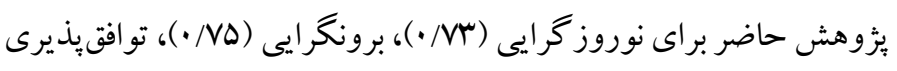

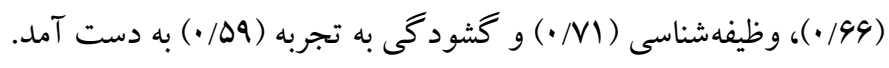

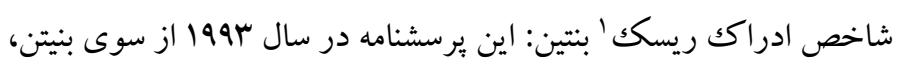
اسلوويكك و سورسون جهت سنجش ادراك افراد از ريسك ساخته شد.

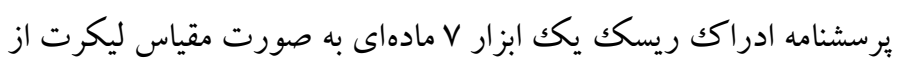

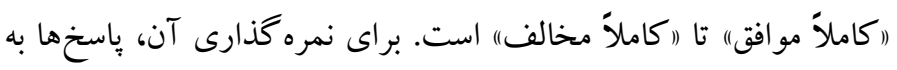

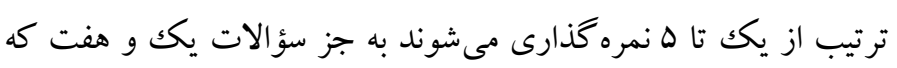

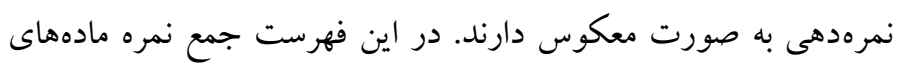

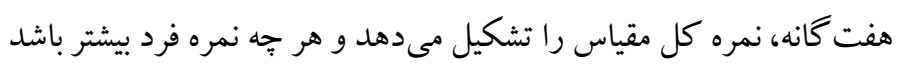

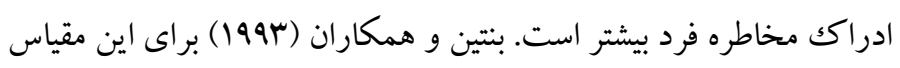

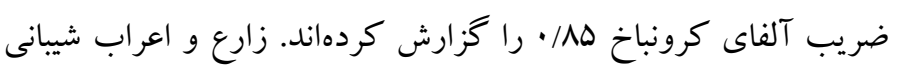

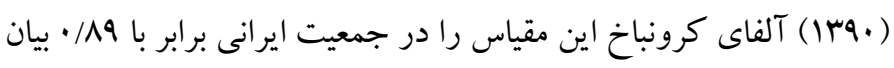

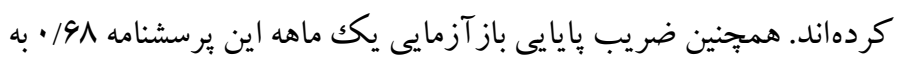

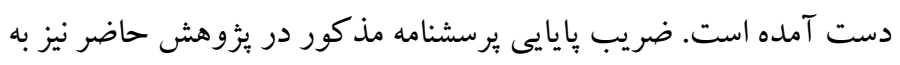
روش آلفاى كرونباخ \^/ • محاسبه شد. شاخص حساسيت اضطر ابى ': شاخص حساسيت اضطر ابى يك بـ برسشنامه خود ززارشدهى است كه از سوى ريس و همكاران (1919) ساخته شده و داراى 19 گويه است. نمره گذارى اين شاخص براساس مقياس رينج

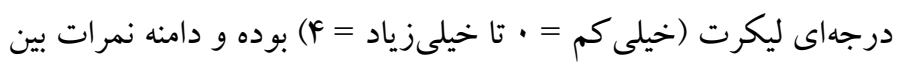

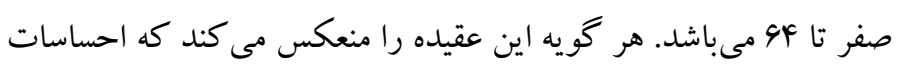
اضطر ابى به صورت ناخوشآ يند تجربه مى شوند و توان منتهى شدن بن به به بيامد آسيبزا را دارند. درجه تجربه ترس از نشانهاى اضطر ابى با نمرات بالاتر

${ }^{2}$. Anxiety Sensitivity Index
از ير سشنامه MERS-CoV (الربيعه، تمسح، العياضى، حسن، الزميل، السبايع

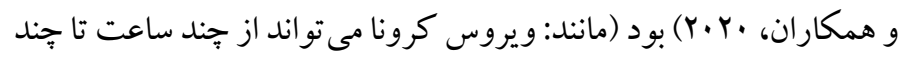

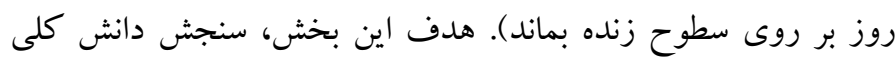

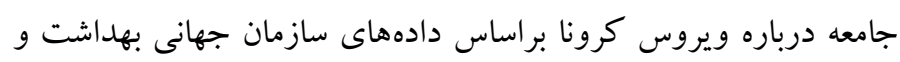
باورهاى عمومى درباره ويروس كرونا بود. بخش دوم شامل اب سؤال براساس طيف ليكرت ه درجهاى از (كاملاً موافقم) (نمره يكك) تا (ركاملاً

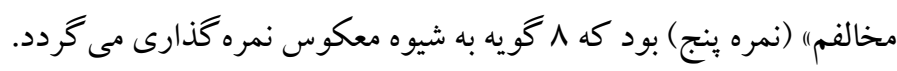

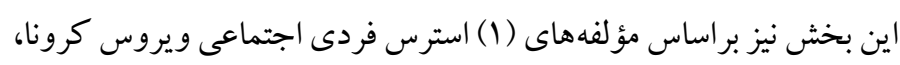

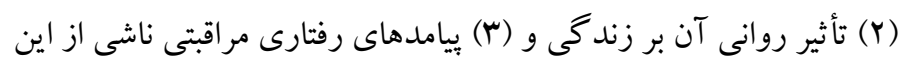
ويروس طراحى شده بود (مانند: از زمان شيوع ويروس كرونا، حساسيتم روى نحوه نفس كشيدنم بيشتر شده است). گويه هاى اين بخش از ويرون

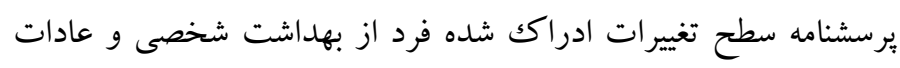

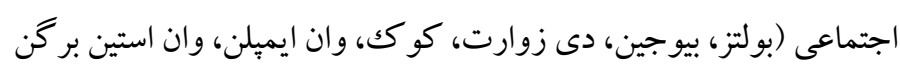

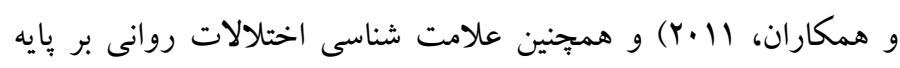

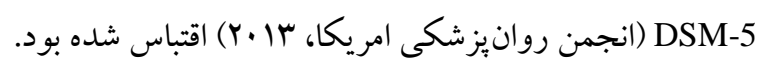

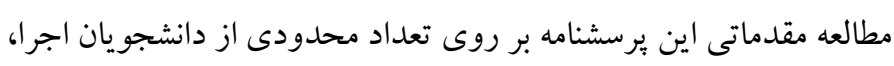

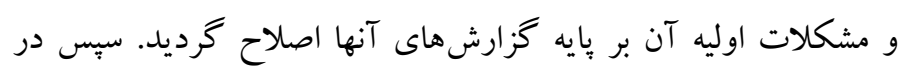

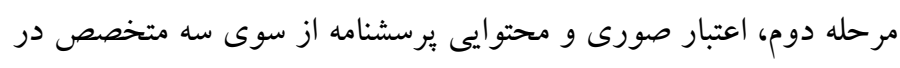

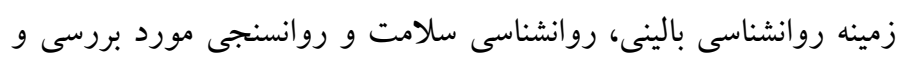

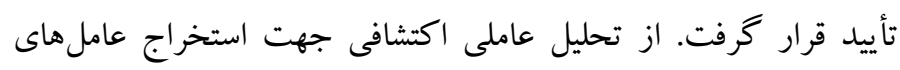
زيربنايى استفاده شد. نتايج، ساختار سه عاملى را مورد تأييد قرار داد. همجينين در بثزوهش حاضر كل مقياس همسانى درونى خوبى را نشان داد

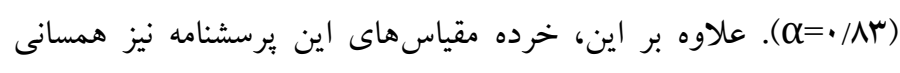

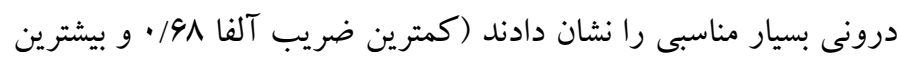

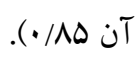

يرسشنامه ينج عامل شخصيت IPIP مقياس شخصيتى IPIP كو

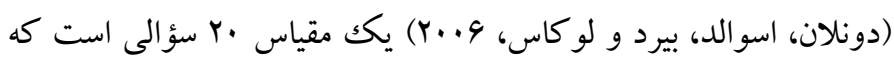

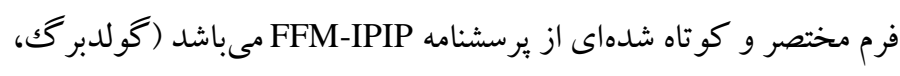

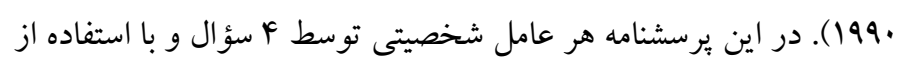

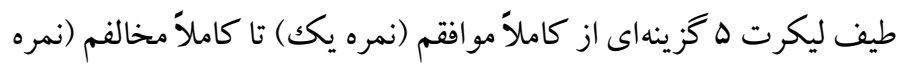

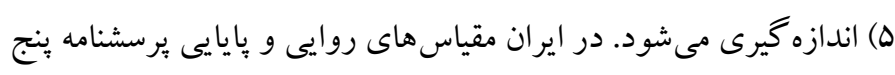

${ }^{1}$. Risk Perception Index 
ييشفرض هاى مدل يابى معادلات ساختارى يرداخته شد. تحقق اين بيش فرض ها بر مناسب بودن استفاده از اين روش آمارى براى بُزوهش حاضر ماري صحه كذاشت.

ييشفرضهاى مدل يابى معادلات ساختارى: از جمله ييشفرضهاى مهم

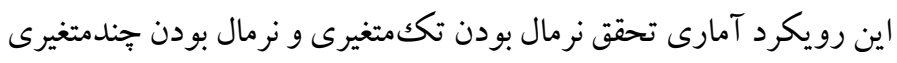

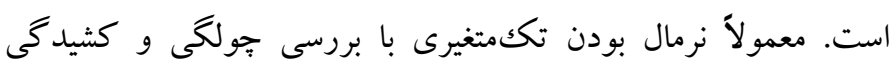

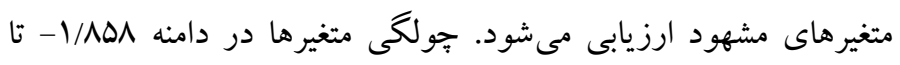

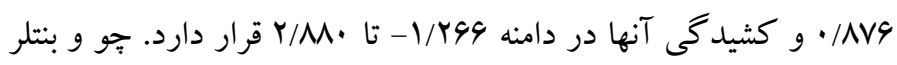

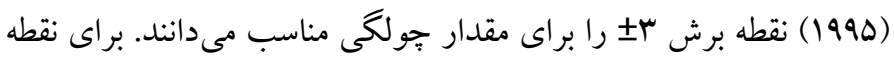

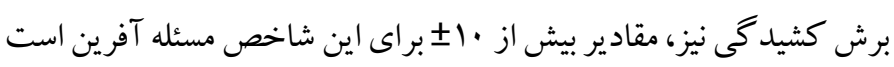

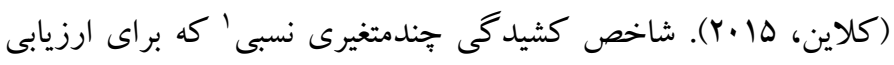

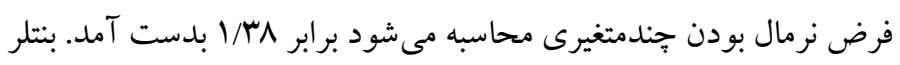

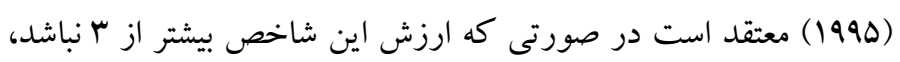
نرمال بودن جندمتغيرى محقق شده است. ماتريس همبستخى بين متغيرهاى

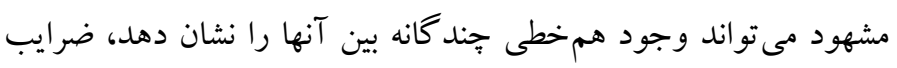

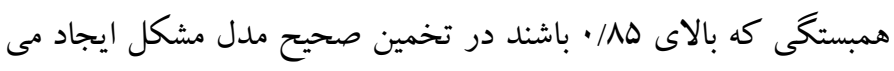

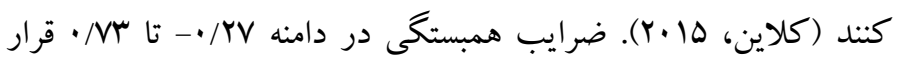

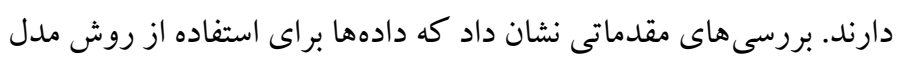
يابى معادلات ساختارى و روش بر آورد حدا كثر درست نمايى مناسب است.

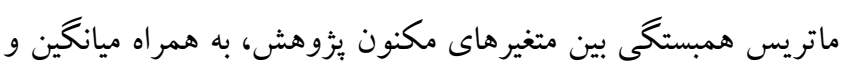

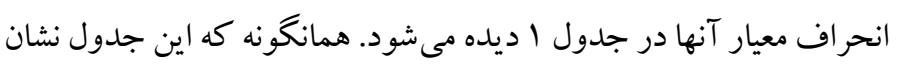

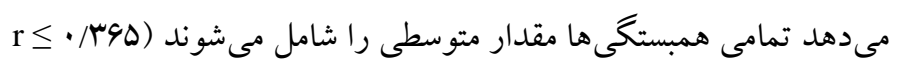
.$(-\cdot / \cdot 90 \leq$
مشخص مى شود. اين شاخص داراى سه عامل ترس از نكر انىهاى بدنى (1)

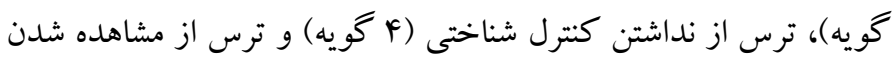

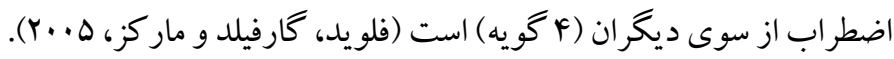
بررسى ويزگىهاى روان سنجى اين شاخص، ثبات درونى (آلفاى

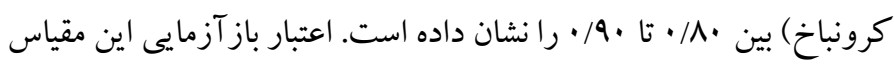

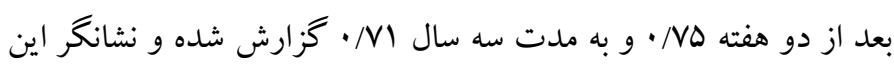

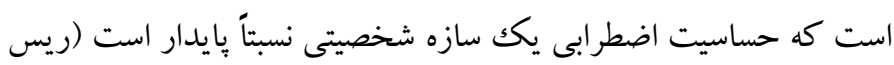

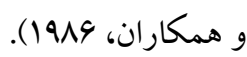
اعتبار اين شـاخص در نمونه ايرانى بر اسـاس سـه روش همسـانى درونى،

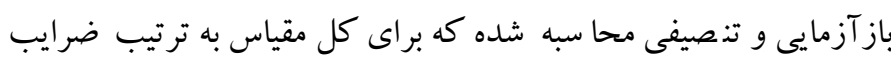

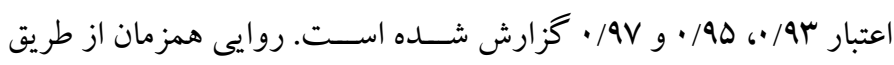

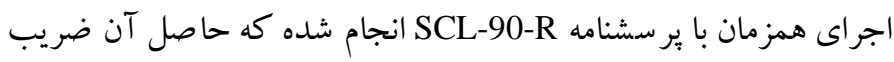

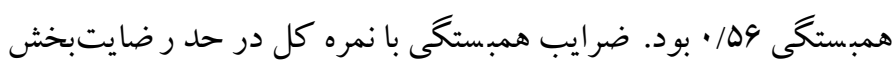

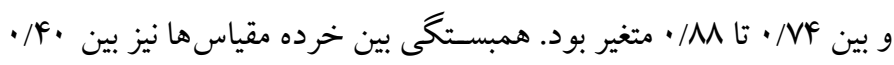

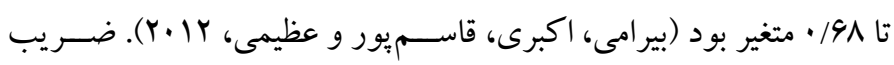

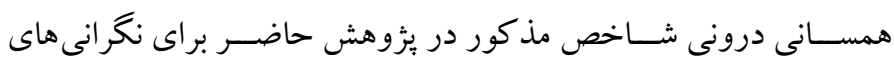

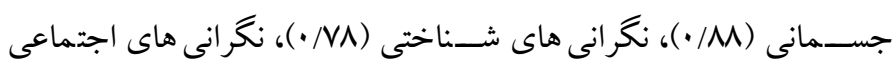
(199/•) و براى كل مقياس (199/•) به دست آمد.

يافته ها در يُوهش حاضر به بررسى يكك مدل ساختارى يرداخته شد. در اين مدل،

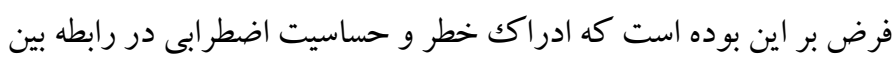

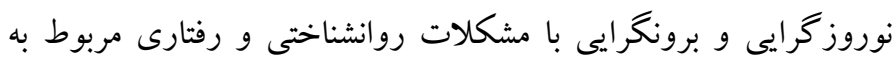

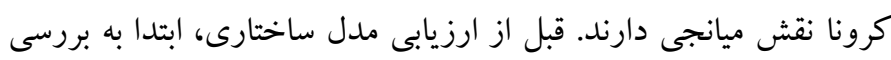

جدول 1. ماتريس همبستغى متغير هاى ثزوهش

\begin{tabular}{|c|c|c|c|c|c|c|c|c|c|}
\hline كشيدگى & جولخى & SD & M & f & $r$ & $r$ & 1 & متغيرها & \\
\hline.$- / 94$. &.$- / 199$ & $\mathrm{r} / \mathrm{W}$ & $\mid r / 9 T$ & & & & 1 & برونگر ايى & 1 \\
\hline$-\cdot / \Delta r$. & (III & $r / 41$ & $\mid 1 / \pi 1$ & & & 1 & $-\cdot / 1 \Delta r^{* * *}$ & نوروز گرايى & $r$ \\
\hline $1 / \cdot 19$ & $\cdot / 199$ & $F / \cdot \Delta$ & $19 / 11$ & & 1 & 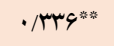 & 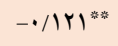 & ادراكك خطر & $r$ \\
\hline$-\cdot$ / MAT & $\cdot / \notin \Delta$ & $1 Y / 99$ & $r \Delta / \uparrow_{A}$ & 1 & $\cdot / r V V^{* * a}$ & $\cdot / \mu F Y^{* * n}$ & $-\cdot / 19 r^{* * * *}$ & حساسيت اضطر ابى & f \\
\hline .1949 & $-\cdot / \Delta r \Lambda$ & $1 . / 40$ & $99 / \mathrm{GV}$ & $\cdot / \pi 90^{* * * *}$ & $-\cdot / Y G \Gamma^{\text {\%क券 }}$ & $-\cdot / Y^{\prime} \Lambda^{* * * *}$ & $-\cdot / \cdot 90^{*}$ & مشكلات كرونا & $\Delta$ \\
\hline
\end{tabular}

\footnotetext{
${ }^{1}$. relative multivariate kurtosis
} 
براى عملياتى كردن متغيرهاى مكنون را دارند. همجنين ارزيابى مدل

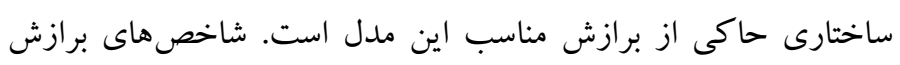

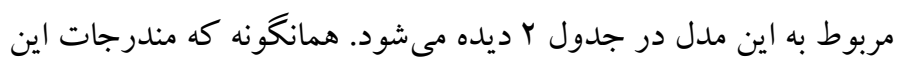
جدول نشان مى دهد تمامى شاخصها در محدوده برازش مناسب مدل قرل مرار

دارند.
مدل اندازه گيرى (تحليل عاملى تأيدى): قبل از ارزيابى مدل ساختارى، شاخصهاى برازش براى مدل اندازه گيرى محاسبه شد. مدل اندازيرى

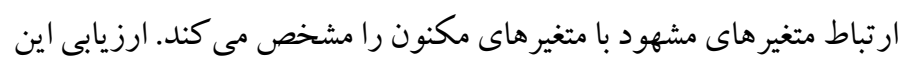

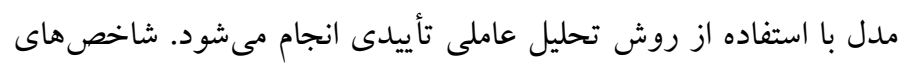

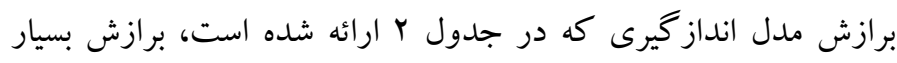
مناسب اين مدل را نشان مىدهد. بنابراين متغيرهاى مشهود توانايى لازم جدول r. شاخص هاى برازش مدل اندازهَيرى و مدل مدل ساختارى

\begin{tabular}{|c|c|c|c|c|c|c|c|c|}
\hline GFI & NFI & CFI & SRMR & RMSEA & $\mathrm{X} 2 / \mathrm{Df}$ & DF & Chi-Square & \\
\hline$\cdot / 90$ &.$/ 94$ & $\cdot / 99$ &.$/ . \Delta r$ &.$/ \cdot \Delta F$ & $r / 91$ & $9 F$ & TVT/AD & مدل اندازهيرى \\
\hline$\cdot / 9 \Delta$ & $\cdot / 9 F$ &.$/ 99$ & $\cdot / \cdot \Delta \Delta$ & $\cdot / \cdot \Delta V$ & $r / .$. & 90 & YND/rY & مدل ساختارى \\
\hline
\end{tabular}

به ترتيب بر متغير ميانجى ادراكك خطر و متغير وابسته كرونا تأثير معنىدارى

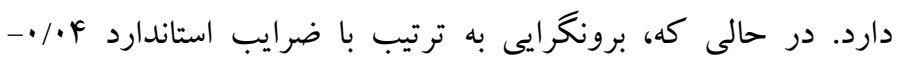

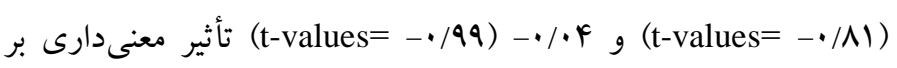
ادراكك خطر و كرونا ندارد. از سوى ديخر، ادراكى خطر و حساسيت

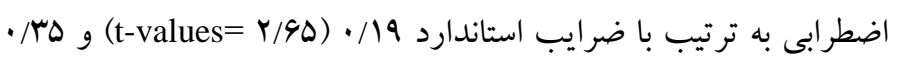
تأثير معنى دارى بر متغير وابسته كرونا دارند. (t-values=9/9•)
مدل ساختارى: اثرات مستقيم: شكل ا مدل ساختارى فرضى را به همراه

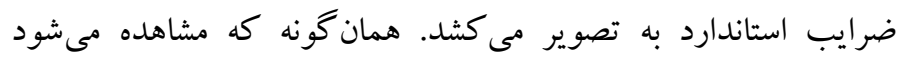

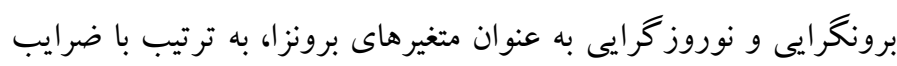

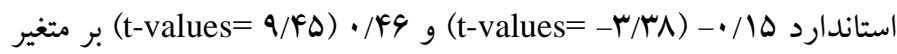
ميانجى حساسيت اضطرابى تأثير معنىدارى دارند. همجنين، نوروز گرايى

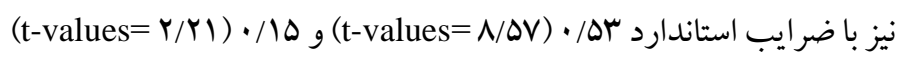

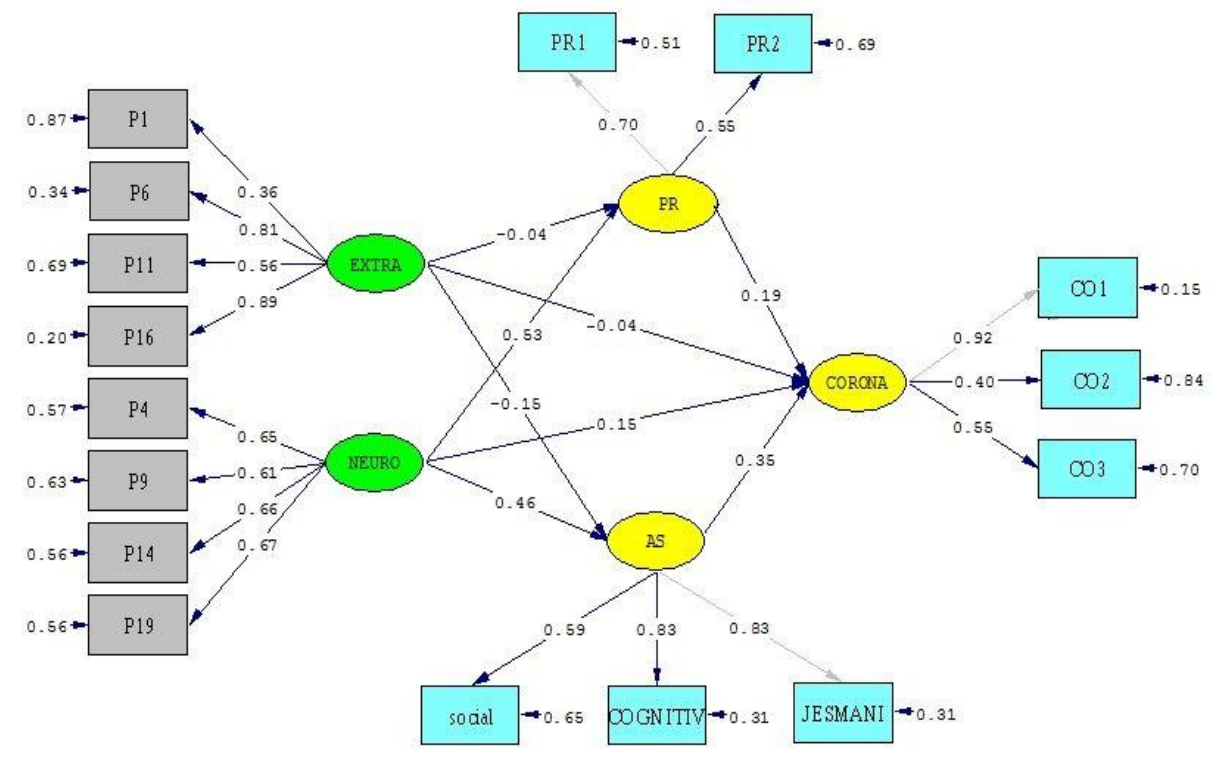

Chi-Square $=285.22, d f=95, P$-value $=0.00000$, RMSEA $=0.056$

شكل ا. مدل ساختارى يخوهش همر اه با ضرايب استاندارد

مى توان هم با مراجعه به سطح معنىدارى و هم با بررسى حدود بوت

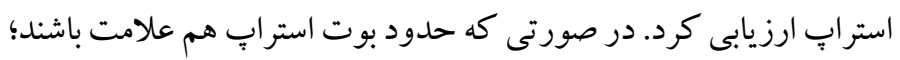

ارزيابى مدل واسطهاى: اثرات غيرمستقيم: براى ارزيابى معنىدارى اثرات

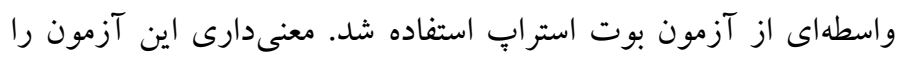


دارى بر مشكلات روانشناختى و رفتارى كرونا دارد. از سوى ديخر، برونگرايى با ميانجيخرى حساسيت اضطرابى بر متغير وابسته مشكلات

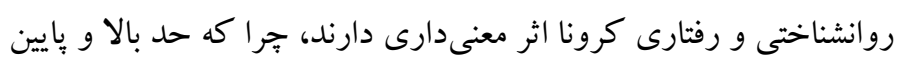

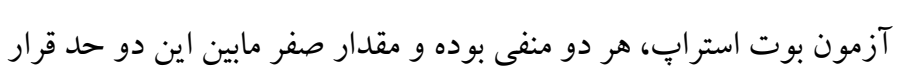
ندارد. در حالى كه، اثر برونگر ايى بر مشكلات روانشناختى و رفتارى كرونى بونا به واسطه ادراكك خطر معنىدار نيست.
يعنى هر دو منفى يا هر دو مثبت باشند، اثر واسطهاى حائز معنىدارى است. نتايج مربوط به اين آزمون در جدول م مشاهده مى دشود.

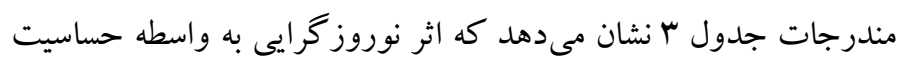
اضطرابى و ادراكك خطر بر متغير وابسته درونزاى كرونا از نظر آمارى معنى دار است. جرا كه حد بالا و پايين آزمون بوت استراب، هر دو مثبت بوده و

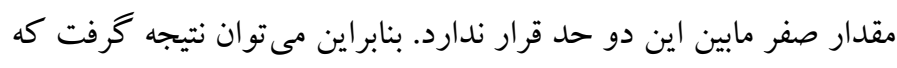
نوروز گرايى به واسطه حساسيت اضطر ابى و ادراك خطر اثر مثبت و معنى

جدول ". شاخص هاى برازش مدل اندازهكيرى و مدل ساختارى

\begin{tabular}{|c|c|c|c|c|c|c|c|}
\hline \multirow{2}{*}{ سطح معنى دارى } & \multirow{2}{*}{ اندازه اثر } & \multirow{2}{*}{ خطاى بر آورد } & \multicolumn{2}{|c|}{ حدود بوت استراب } & \multirow{2}{*}{ متغير وابسته } & \multirow{2}{*}{ متغير واسط } & \multirow{2}{*}{ متغير مستقل } \\
\hline & & & حد يايين & حد بالا & & & \\
\hline$\cdot / D F V$ & $-\cdot / \cdot \cdot \wedge$ &.$/ .14$ & $-\cdot / \cdot r$. &.$/ .14$ & كرونا & ادراكك خطر & برونگرايى \\
\hline.$/ 1$ & $-\cdot / \cdot \Delta r$ & .1 .19 & $-\cdot / \cdot \wedge r$ & $-\cdot / \cdot 11$ & كرونا & حساسيت اضطر ابى & برونگر ايى \\
\hline . ro & $\cdot / \ldots$ & .1 .94 & $\cdot / \cdot \mathrm{rV}$ &.$/ \mathrm{Vr}$ & كرونا & ادراكك خطر & نوروز گرايى \\
\hline.$\cdots$ &.$/ 191$ & $\cdot / 1 \cdot r$ & $\cdot / 1 \cdot v$ & $\cdot / r \cdot F$ & كرونا & حساسيت اضطر ابى & نوروز گرايى \\
\hline
\end{tabular}

يرخطر را تعديل مى كند. در توضيح اين مطلب مى توان مطرح كرد با توجه

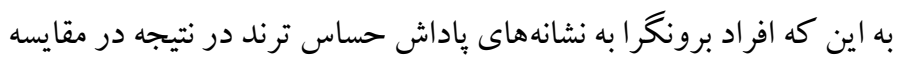

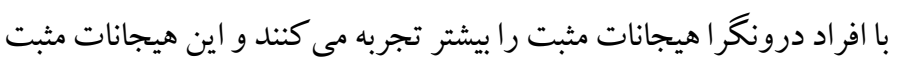
مانند يكك سبر دفاعى در برابر مشكلات مربوط به بيمارىهاى مختلف از ماز

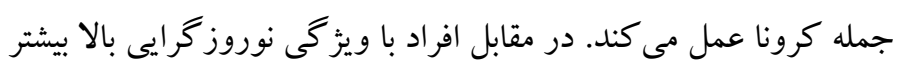

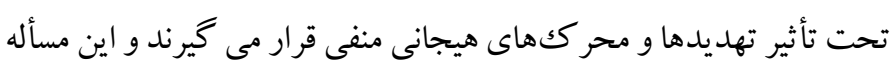
باعث تجربه تنش بيشتر در مقابل بيمارىهاى مختلف مىشود (لو كاس و و

$$
\text { داينر، (ب... (Y). }
$$

يكى از يافتهاى بزوهش حاضر ارتباط نوروز خرايى با ادراكك خطر است.

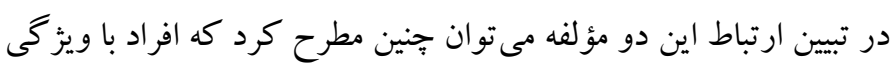

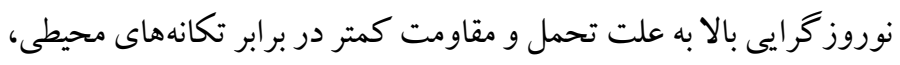

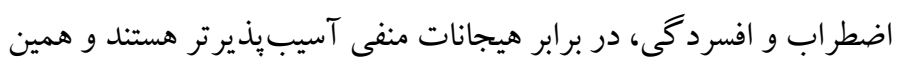

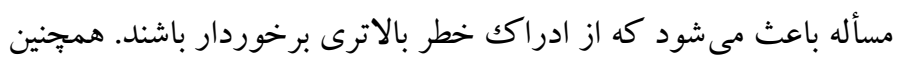

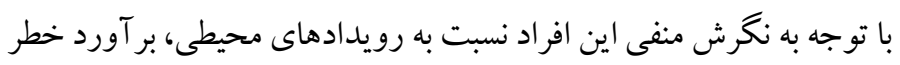

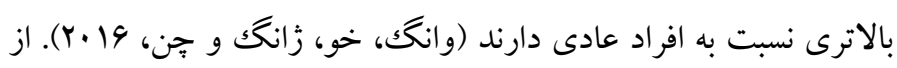

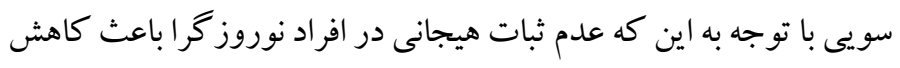

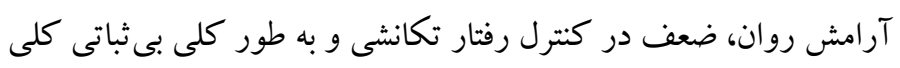

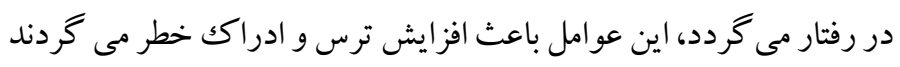

بحث و نتيجه تيرى يزوهش حاضر با هدف مطالعه رابطه نوروز گر ايى و برونگ ائى با مشكلات روانشناختى و رفتارى كرونا با ميانجيخرى ادراكى خطر و حساسيت

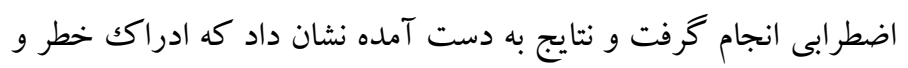

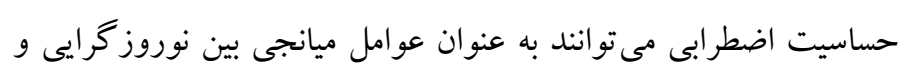
برونگر ايى با مشكلات روانشناختى و رفتارى كرونا در نظر كرفته شوند.

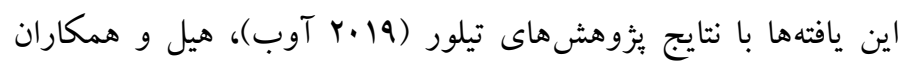

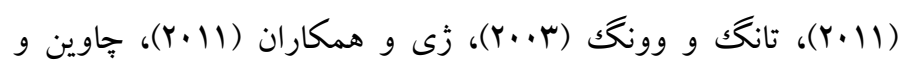

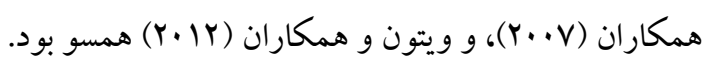

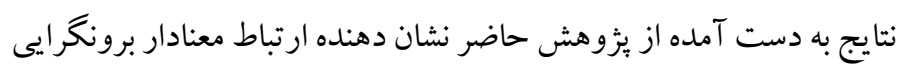

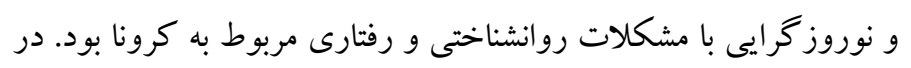

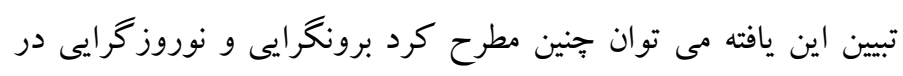

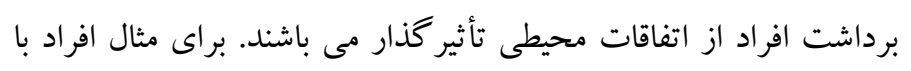

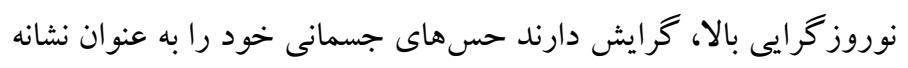

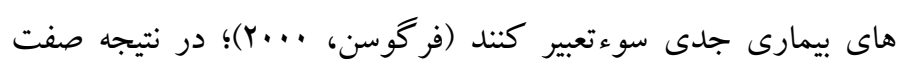

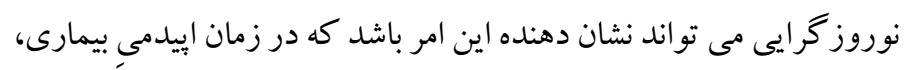

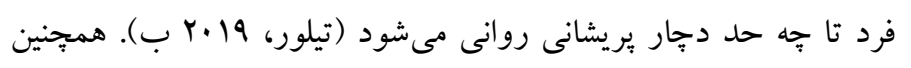

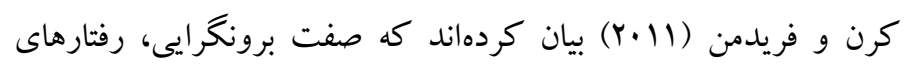


نمايند (تيلور، 19 19 ب) اين توجه افراطى به بدن باعث خواهد شد كه

$$
\text { مشكلات مربوط به كرونا تشديد شود. }
$$

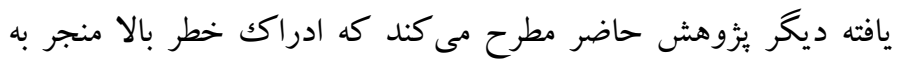
مشكلات روانشناختى و رفتارى مربوط به كرونا مى گردد. در تبيين اين يافته

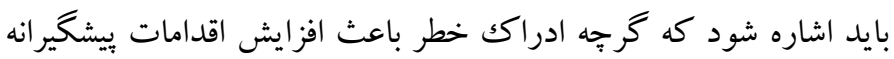
مىشود و در بيمارىهاى همه گير ييشخيرى مسأله مهمى است (كراس،

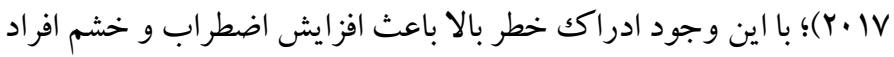

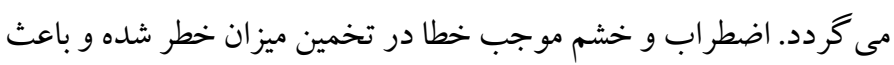

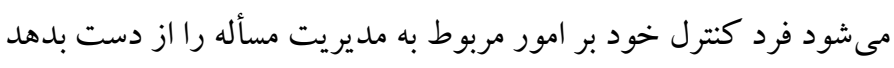

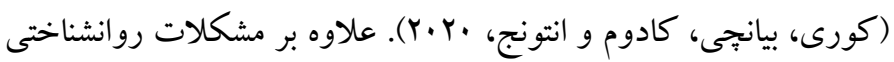

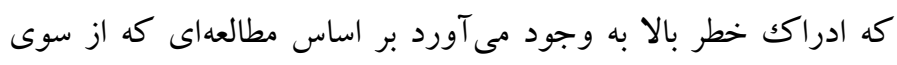

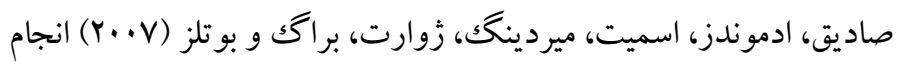

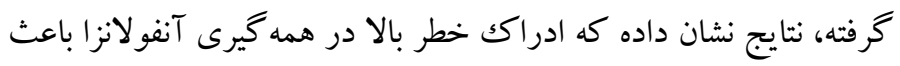
كاهش رفتارهاى محافظتى در بلندمدت نيز شده است.

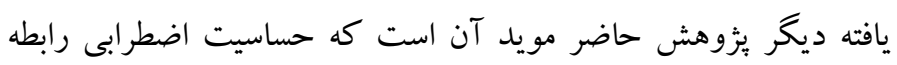

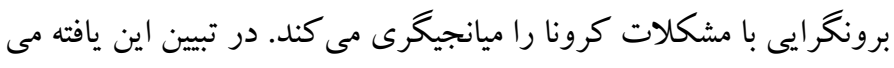

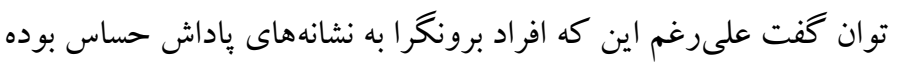

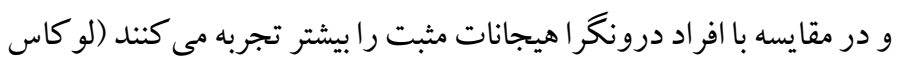

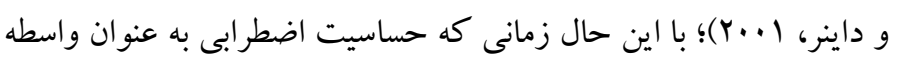

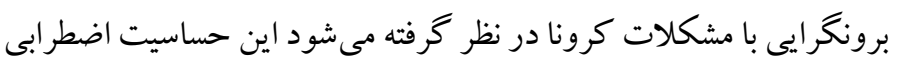

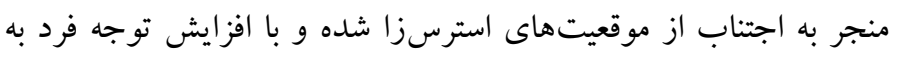

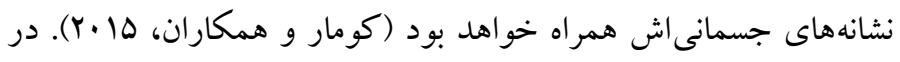

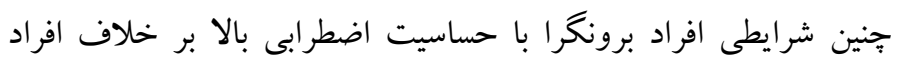

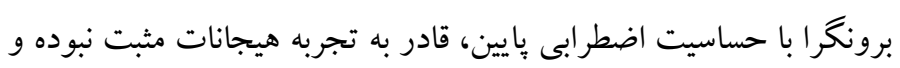

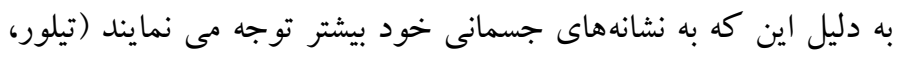

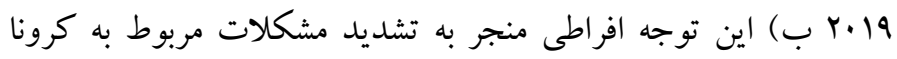

در نهايت آخرين يافته بثوهش حاضر نشان مىدهد كه ادراك خطر و

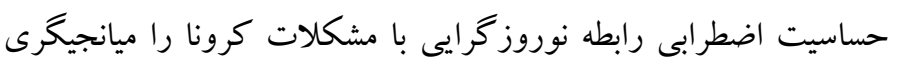

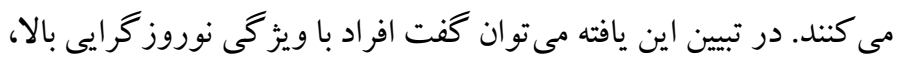
به دليل فقدان مهارتهاى ساز كارى مناسب، بيشتر تحت تأثير تهديدها و و

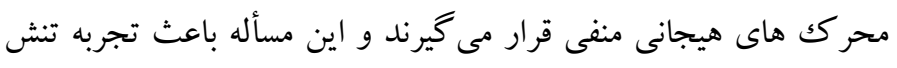

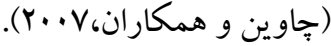
از ديخر يافتهاى يثزوهش حاضر رابطه بين نوروز خرايى و حساسيت

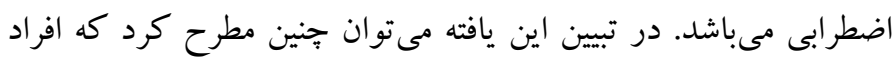

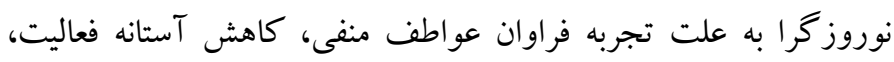
مشكل در بازدارى و كنترل هيجان، تجارب اضطرابى بالايى دارند و اين

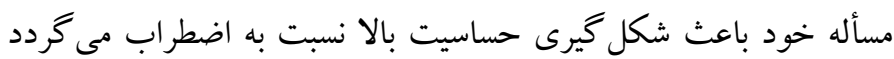

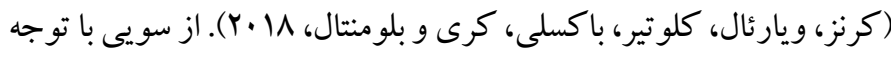

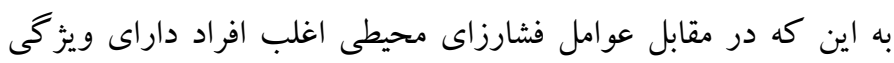

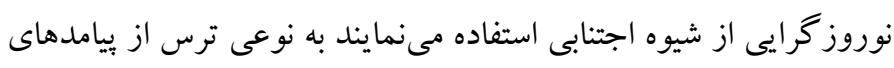
اضطراب باعث افزايش حساسيت نسبت به اضطراب مى گردد (كومار و و

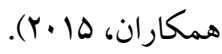
از ديخر يافته هاى يزوهش حاضر رابطه بين برونخر ايى و حساسيت اضطر ابى

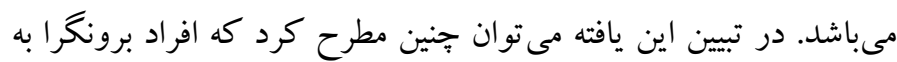

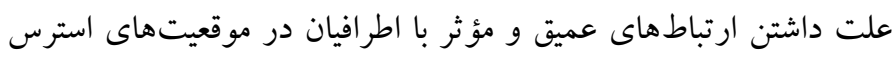

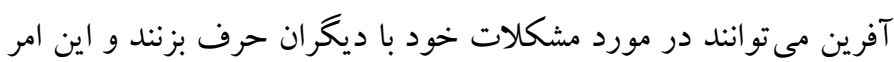

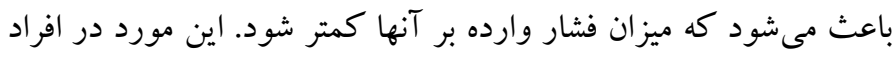

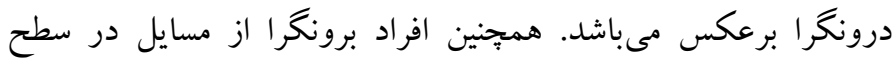

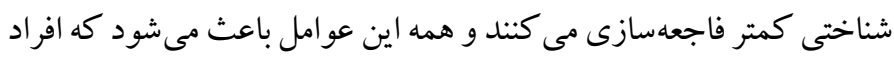

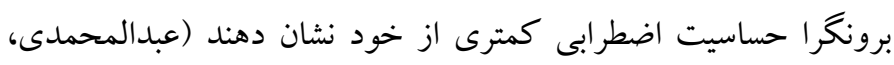

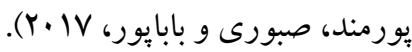
از سويى يافتهاى يثزوهش حاضر نشان مىدهد كه حساسيت اضطر بـى بالا باعث مشكلات بيشترى در زمان شيوع كرونا شده است. حساسيت برون

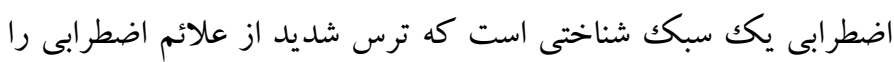

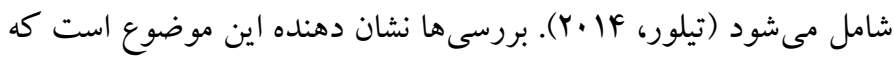
هر جقدر حساسيت اضطرابى بالاتر باشد فرد استرس بيشترى را تجربه

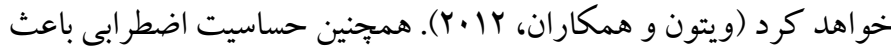
خواهد شد كه افراد افكار و اعمال وسواسى بيشترى از خود نشان دهند

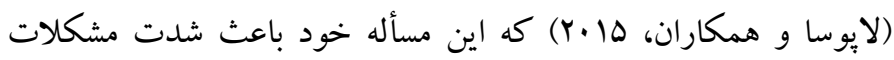
روانشناختى و رفتارى مربوط به كرونا خواهد شد. از سويى افراد نسبت به مانه نشانهاى بدنى خود گوش به زنغك هستند و بيش از اندازه به آنها توجه

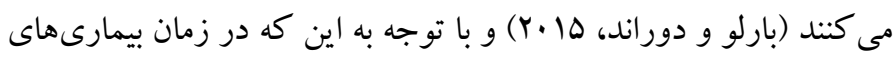

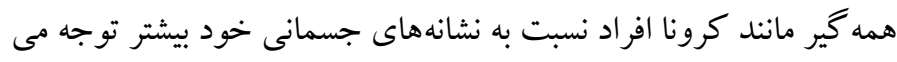




\section{ملاحضات اخلاقى}

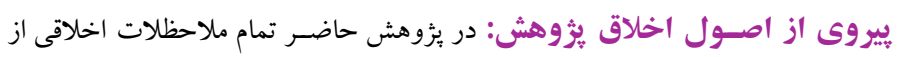
قبيل رعايت اصل رازدارى، محرمانه بودن اطلاعات و اصل رضايت آكاهانه رعايت شد.

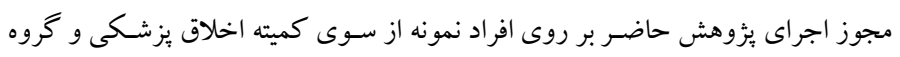

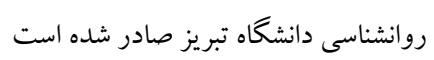
حامى مالى: بثروهش حاضر به صورت مستقل و بدون حمايت مالى انجام شده است.

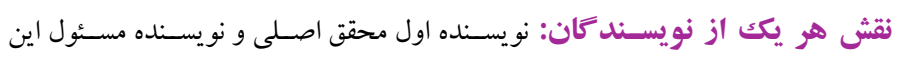
يُزوهش است. ساير نويسند كان به عنوان نويسنده همكار در اين ئزوهش مشار كت داشته

$$
\text { و سهم مشار كت آنها برابر است. }
$$

تضاد منافع: نويسند گان هيج تضاد منافعى در رابطه با اين يثوهش اعلام نمى بـمايند.

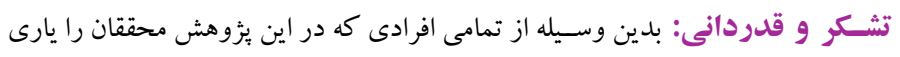
نمودند تشكر و قدردانى مى كردد.

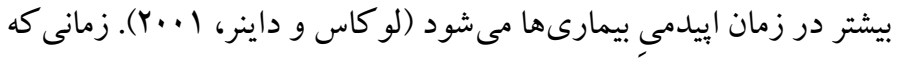
ادراكك خطر بالا و حساسيت اضطرابى در تعامل با نوروز گرايى قرار مى گيرند، اثرات نوروز خر ايى را تشديد نموده و منجر به اجتناب فرد از هيجان هاى منفى و افزايش توجه وى بر نشانه هاى جسمانى اش خو اهند شد (جاوين

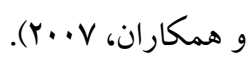

از جمله محدوديت هاى بثزوهش حاضر مىتوان به استفاده از نمونه در دسترس به صورت آنلاين با قوميت، فرهنگك و طبقات اجتماعى - اقتصادى مختلف اشاره كرد كه مىتواند يافته هاى يزوهش را مشتبه سازد. هميجنين با توجه به اين كه اكثر شركت كنندكان در يثوهش حاضر رازنان تشكيل مى دادند در تعميم يافته هاى يُزوهش به جامعه مردان بايد احتياط نمود. با توجه به اين محدوديتها توصيه مىشود بزوهش هاى آتى نقش تعديل كننده متغيرهايى مثل جنسيت، قوميت، فرهنگك و وضعيت اجتماعى - اقتصادى را بررسى كرده و يا كروهها را از نظر متغيرهاى ذكر شده همتاسازى كنند. 


\section{References}

Abdolmohamadi, K., Seyed Pourmand, N. S., Sabouri Moghadam, H., \& Babapour Kheyradin, J. (2017). The Somatization Predictions Derived from Personal Characteristics. International Journal of Behavioral Sciences, 11(3), 86-89. [Link]

Abramowitz, J. S., \& Blakey, S. M. (2020). Clinical handbook of fear and anxiety: Maintenance processes and treatment mechanisms. American Psychological Association. [Link]

Al-Rabiaah, A., Temsah, M. H., Al-Eyadhy, A. A., Hasan, G. M., Al-Zamil, F., Al-Subaie, S., ... \& Somily, A. M. (2020). Middle East Respiratory SyndromeCorona Virus (MERS-CoV) associated stress among medical students at a university teaching hospital in Saudi Arabia. Journal of Infection and Public Health 13, 687-691. [Link]

Bajcar, B., \& Babiak, J. (2020). Neuroticism and cyberchondria: The mediating role of intolerance of uncertainty and defensive pessimism. Personality and Individual Differences, 162, 110006. [Link]

Banerjee, D. (2020). The COVID-19 outbreak: Crucial role the psychiatrists can play. Asian journal of psychiatry, 50, 102014. [Link]

Barlow, D. H., \& Durand, V. M. (2015). Abnormal Psychology: An Integrated Approach $7^{\text {th }}$ Edition. Cengage Learning Publisher. [Link]

Beirami, M., Akbari, E., Qasempour, A., Azimi, Z. (2012). An Investigation of Anxiety Sensitivity, MetaWorry and Components of Emotion Regulation in Students with and without Social Anxiety. Clinical Psychology Studies, 2(8), 40-69. (Persian). [Link]

Benthin, A., Slovic, P., \& Severson, H. (1993). A psychometric study of adolescent risk perception. Journal of Adolescence, 16(2), 153-168. [Link]

Bentler, P. M. (1995). EQS structural equations program manual (Vol. 6). Encino, CA: Multivariate software. [Link]

Bults, M., Beaujean, D. J., de Zwart, O., Kok, G., van Empelen, P., van Steenbergen, J. E., ... \& Voeten, H. A. (2011). Perceived risk, anxiety, and behavioural responses of the general public during the early phase of the Influenza A (H1N1) pandemic in the Netherlands: results of three consecutive online surveys. BMC public health, 11(1), 2. [Link]

Cao, W., Fang, Z., Hou, G., Han, M., Xu, X., Dong, J., \& Zheng, J. (2020). The psychological impact of the COVID-19 epidemic on college students in China. Psychiatry research, 112934. [Link]
Cerase, A. (2017). Risk and Communication. Theories, Models, Problems. Egea, Rome. [Link]

Chauvin, B., Hermand, D., \& Mullet, E. (2007). Risk perception and personality facets. Risk Analysis: An International Journal, 27(1), 171-185. [Link]

Chou, C. P., \& Bentler, P. M. (1995). Estimates and tests in structural equation modeling. In: Hoyle, R. H. editor. Structural Equation Modeling: Concepts, Issues, and Application. SAGE: Thousand Oaks, California. [Link]

Chowdhury, N., Kevorkian, S., Sheerin, C. M., Zvolensky, M. J., \& Berenz, E. C. (2016). Examination of the association among personality traits, anxiety sensitivity, and cannabis use motives in a community sample. Journal of Psychopathology and Behavioral Assessment, 38(3), 373-380. [Link]

Commodari, E. (2017). The role of sociodemographic and psychological variables on risk perception of the flu. SAGE Open, 7(3), 2158244017718890. [Link]

Cooper, A. J., Smillie, L. D., \& Corr, P. J. (2010). A confirmatory factor analysis of the Mini-IPIP fivefactor model personality scale. Personality and Individual Differences, 48(5), 688-691. [Link]

Cori, L., Bianchi, F., Cadum, E., \& Anthonj, C. (2020). Risk Perception and COVID-19. International journal of environmental research and public health, 17(9), 3114. [Link]

Donnellan, M. B., Oswald, F. L., Baird, B. M., \& Lucas, R. E. (2006). The mini-IPIP scales: tiny-yeteffective measures of the Big Five factors of personality. Psychological assessment, 18(2), 192. [Link]

Duan, L., \& Zhu, G. (2020). Psychological interventions for people affected by the COVID-19 epidemic. The Lancet Psychiatry, 7(4), 300-302. [Link]

Fergus, T. A., \& Spada, M. M. (2018). Moving toward a metacognitive conceptualization of cyberchondria: Examining the contribution of metacognitive beliefs, beliefs about rituals, and stop signals. Journal of anxiety disorders, 60, 11-19. [Link]

Ferguson, E. (2000). Hypochondriacal concerns and the five factor model of personality. Journal of Personality, 68(4), 705-724. [Link]

Floyd, M., Garfield, A., \& LaSota, M. T. (2005). Anxiety sensitivity and worry. Personality and Individual Differences, 38(5), 1223-1229. [Link]

Goldberg, L. R. (1990). An alternative" description of personality": the big-five factor structure. Journal of personality and social psychology, 59(6), 1216. [Link] 
Goyal, K., Chauhan, P., Chhikara, K., Gupta, P., \& Singh, M. P. (2020). Fear of COVID 2019: First suicidal case in India. Asian journal of psychiatry, 49, 101989. [Link]

Harris, K., English, T., Harms, P. D., Gross, J. J., Jackson, J. J., \& Back, M. (2017). Why Are Extraverts More Satisfied? Personality, Social Experiences, and Subjective Well-Being in College. European Journal of Personality, 31(2), 170-186. [Link]

Hill, P. L., Turiano, N. A., Hurd, M. D., Mroczek, D. K., \& Roberts, B. W. (2011). Conscientiousness and longevity: an examination of possible mediators. Health Psychology, 30(5), 536. [Link]

Karami, Z., Sabzi, R., Chegini, M., Herfedoost, M. (2012). Evaluation of psychometric properties of a 20 -item five personality factors questionnaire. 1st National Conference on Personality and Modern Life (Persian). [Link]

Kearns, N. T., Villarreal, D., Cloutier, R. M., Baxley, C., Carey, C., \& Blumenthal, H. (2018). Perceived control of anxiety as a moderator in the relationship between anxiety sensitivity and problematic alcohol use among adolescents. Journal of adolescence, 63, 41-50. [Link]

Kendler, K. S., Gatz, M., Gardner, C. O., \& Pedersen, N. L. (2006). Personality and major depression: a Swedish longitudinal, population-based twin study. Archives of general psychiatry, 63(10), 11131120. [Link]

Kern, M. L., \& Friedman, H. S. (2011). Personality and pathways of influence on physical health. Social and Personality Psychology Compass, 5(1), 76-87. [Link]

Kline RB. (2015). Principles and practice of structural equation modeling .3nd Ed. New York: Guilford. [Link]

Kumar, S., Vats, G., Sonare, D., Kachhawha, D. (2015). The Personality Characteristics and Quality of Life in Psoriasis Patients. International Journal of Science and Research (IJSR): 78-96. [Link]

Laposa, J. M., Collimore, K. C., Hawley, L. L., \& Rector, N. A. (2015). Distress tolerance in OCD and anxiety disorders, and its relationship with anxiety sensitivity and intolerance of uncertainty. Journal of Anxiety Disorders, 33, 8-14. [Link]

Lima, M. L. (2004). On the influence of risk perception on mental health: living near an incinerator. Journal of environmental psychology, 24(1), 71-84. [Link]

Lucas, R. E., \& Diener, E. (2001). Understanding extraverts' enjoyment of social situations: The importance of pleasantness. Journal of personality and social psychology, 81(2), 343. [Link]

Reiss, S., Peterson, R. A., Gursky, D. M., \& McNally, R. J. (1986). Anxiety sensitivity, anxiety frequency and the prediction of fearfulness. Behaviour research and therapy, 24(1), 1-8. [Link]

Sadique, M. Z., Edmunds, W. J., Smith, R. D., Meerding, W. J., De Zwart, O., Brug, J., \& Beutels, P. (2007). Precautionary behavior in response to perceived threat of pandemic influenza. Emerging infectious diseases, 13(9), 1307. [Link]

Tan, C. S., \& Lee, Q. W. (2017). The role of self-esteem and social support in the relationship between extraversion and happiness: a serial mediation model. Current Psychology, 36(3), 556-564. [Link]

Tang, C. S., \& Wong, C. Y. (2003). An outbreak of the severe acute respiratory syndrome: predictors of health behaviors and effect of community prevention measures in Hong Kong, China. American Journal of Public Health, 93(11), 18871888. [Link]

Taylor, S. (2019a). The Psychology of Pandemics: Preparing for the Next Global Outbreak of Infectious Disease. Cambridge Scholars Publishing. [Link]

Taylor, S. (2019b). Anxiety sensitivity. In j. S. Abramowitz \& S. M. Blakey (Eds.), Clinical handbook of fear and anxiety: Psychological processes and treatment mechanisms. Washington, DC: American Psychological Association. [Link]

Taylor, S. (Ed.). (2014). Anxiety sensitivity: Theory, research, and treatment of the fear of anxiety. Routledge. [Link]

Wang, C. M., Xu, B. B., Zhang, S. J., \& Chen, Y. Q. (2016). Influence of personality and risk propensity on risk perception of Chinese construction project managers. International Journal of Project Management, 34(7), 1294-1304. [Link]

Wheaton, M. G., Abramowitz, J. S., Berman, N. C., Fabricant, L. E., \& Olatunji, B. O. (2012). Psychological predictors of anxiety in response to the H1N1 (swine flu) pandemic. Cognitive Therapy and Research, 36(3), 210-218. [Link]

Xie, X. F., Stone, E., Zheng, R., \& Zhang, R. G. (2011). The 'Typhoon Eye Effect': determinants of distress during the SARS epidemic. Journal of Risk Research, 14(9), 1091-1107. [Link]

Zare, H., \& Aerab Sheibani, K. H. (2012). Reliability and validity of decision making styles questionnaire in Iranian students. Psychological Research, 14(2), 112-125. (Persian). [Link] 